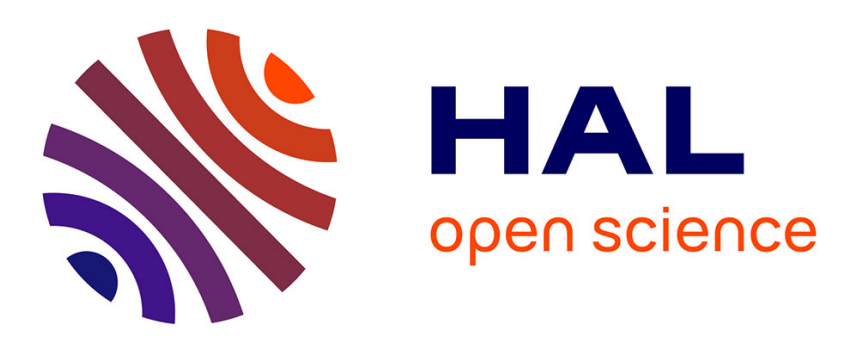

\title{
Competition between 3D structural inheritance and kinematics during rifting: Insights from analogue models
}

Frank Zwaan, Pauline Chenin, Duncan Erratt, Gianreto Manatschal, Guido Schreurs

\section{- To cite this version:}

Frank Zwaan, Pauline Chenin, Duncan Erratt, Gianreto Manatschal, Guido Schreurs. Competition between 3D structural inheritance and kinematics during rifting: Insights from analogue models. Basin Research, 2021, 10.1111/bre.12642 . insu-03514207

\section{HAL Id: insu-03514207 https://hal-insu.archives-ouvertes.fr/insu-03514207}

Submitted on 6 Jan 2022

HAL is a multi-disciplinary open access archive for the deposit and dissemination of scientific research documents, whether they are published or not. The documents may come from teaching and research institutions in France or abroad, or from public or private research centers.
L'archive ouverte pluridisciplinaire HAL, est destinée au dépôt et à la diffusion de documents scientifiques de niveau recherche, publiés ou non, émanant des établissements d'enseignement et de recherche français ou étrangers, des laboratoires publics ou privés. 


\title{
Competition between 3D structural inheritance and kinematics during rifting: Insights from analogue models
}

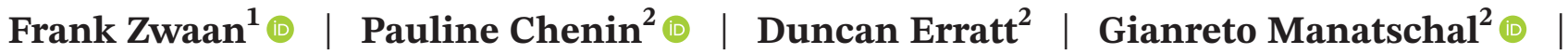 \\ Guido Schreurs ${ }^{1}$ (๑)
}

${ }^{1}$ University of Bern, Institute of Geological Sciences, Bern, Switzerland

${ }^{2}$ Université de Strasbourg, CNRS, ENGEES, ITES UMR 7063, Strasbourg, France

\section{Correspondence}

Frank Zwaan, Institute of Geological

Sciences, University of Bern,

Baltzerstrasse 1+3, 3012 Bern,

Switzerland.

Email: frank.zwaan@geo.unibe.ch

\section{Funding information}

Swiss National Science Foundation, Grant/Award Number: 200021-178731

\begin{abstract}
The competition between the impact of inherited weaknesses and plate kinematics determines the location and style of deformation during rifting, yet the relative impacts of these 'internal' and 'external' factors remain poorly understood, especially in 3D. In this study, we used brittle-viscous analogue models to assess how multiphase rifting, that is changes in plate divergence rate or direction, and the presence and orientation of weaknesses in the competent mantle and crust, influences rift evolution. We find that the combined reactivation of mantle and crustal weaknesses without any kinematic changes already creates complex rift structures. Divergence rates affect the strength of the weak lower crustal layer and hence the degree of mantle-crustal coupling; slow rifting decreases coupling, so that crustal weaknesses can dominate deformation localisation and surface structures, whereas fast rifting increases coupling and deformation related to mantle weaknesses can have a dominant surface expression. Through a change from slow to fast rifting mantle-related deformation can overprint structures that previously formed along (differently oriented) crustal weaknesses. Conversely, a change from fast to slow rifting may shift deformation from mantlecontrolled towards crust-controlled. When changing divergence directions, structures from the first rifting phase may control where subsequent deformation occurs, but only when they are sufficiently well developed. We furthermore place our results in a larger framework of brittle-viscous rift modelling results from previous experimental studies, showing the importance of general lithospheric layering, divergence rate, the type of deformation in the mantle, and finally upper crustal structural inheritance. The interaction between these parameters can produce a variety of deformation styles that may, however, lead to comparable end products. Therefore, careful investigation of the distribution of strain localisation, and to an equal extent of basin depocenter locations over time is required to properly determine the evolution of complex rift systems, providing an incentive to revisit various natural examples.
\end{abstract}

\section{K E Y W O R D S}

analogue modelling, continental break-up, multiphase rifting, structural inheritance

This is an open access article under the terms of the Creative Commons Attribution License, which permits use, distribution and reproduction in any medium, provided 


\section{1 | INTRODUCTION}

During the early stages of continental rifting, deformation is often localised along structural weaknesses inherited from previous tectonic phases (e.g. Bonini et al., 1997; Corti, 2012; Morley et al., 1990; Nelson et al., 1992; Wilson, 1966). These inherited weaknesses may be situated anywhere in the lithosphere, but their impact is more significant when they are located in competent layers. The strength of stable thermally equilibrated continental lithosphere is generally considered to be dominated by a competent upper crust and a competent upper mantle, separated by a ductile lower crustal layer (e.g. Brun, 1999; Burov, 2011; Burov \& Watts, 2006; Zwaan et al., 2019). Hence the reactivation of weaknesses in these competent upper crust and upper mantle layers is expected to control subsequent rift development (Chenin \& Beaumont, 2013).

Tectonic modellers have often focused on the influence of either mantle or crustal weaknesses on the evolution of rift structures (e.g. Agostini et al., 2009; Autin et al., 2010, 2013; Bellahsen \& Daniel, 2005; Brun \& Tron, 1993; Brune \& Autin, 2013; Chenin \& Beaumont, 2013; Chenin, James, et al., 2019; Duclaux et al., 2020; Dyksterhuis et al., 2007; Kettermann et al., 2016; Le Calvez \& Vendeville, 2002; Liao \& Gerya, 2015; Maestrelli et al., 2020; Molnar et al., 2017, 2018, 2019; Van Wijk, 2005; Wang et al., 2021; Wenker \& Beaumont, 2018; Zwaan et al., 2016, 2019; Zwaan, Schreurs, \& Adam, 2018). However, until recently, only limited attention was directed to the question of how mantle and crustal weaknesses may interact and compete during rifting, especially in three dimensions. A recent analogue modelling study by Molnar et al. (2020) showed that mantle weaknesses may determine the general rift trend, whereas crustal weaknesses oriented obliquely to this trend may segment or partition the rift structure on a smaller scale. In a subsequent publication, Zwaan et al. (2021a) improved upon this study by systematically testing how mantle and crustal weaknesses interact under constant kinematic settings. Their model results revealed the development of complex rift structures with different structural orientations under a constant kinematic setting, showing that structural weaknesses can be a highly dominant factor in a rift system. The authors pointed out, as was previously suggested by Reeve et al. (2015), that the reactivation of pre-existing crustal and mantle weaknesses during a single phase of rifting could establish a rift system with structural trends that would otherwise suggest a multiphase rifting history involving changes in large-scale plate divergence directions over time.

However, Zwaan et al. (2021a) did not test the impact of multiphase rifting, which previous work has shown to be important during continental rifting (Bonini et al., 1997; Brune et al., 2018; Dubois et al., 2002; Henza et al.,

\section{Highlights}

- We model 3D structural inheritance and multiphase rifting with changing kinematics

- Combined reactivation of 3D mantle and crustal weaknesses creates complex rift structures

- Divergence rate strongly controls which (type of) inherited weakness dominates rift development

- When divergence direction changes, welldeveloped structures control subsequent deformation

- Our model results provide a strong incentive to revisit the interpretation of natural examples

2010, 2011; Heron et al., 2019; Wang et al., 2021; Withjack et al., 2017). Traditionally, multiphase rifting is associated with changing plate divergence directions, as has been proposed for, for example the Main Ethiopian Rift (Bonini et al., 1997), the Turkana Depression in East Africa (Wang et al., 2021), the Labrador Sea (Heron et al., 2019) and the Afar Rift (Chorowicz et al., 1999; Zwaan et al., 2020b, Zwaan, Corti, et al., 2020). These changes in divergence direction are associated with a reactivation of previous rift structures, or even a clear rearrangement of structural orientations to fit the new tectonic situation, depending on the prominence of structures formed during the first phase (Henza et al., 2010, 2011; Wang et al., 2021). Another, less studied type of multiphase rifting involves changes in divergence rates over time. Recently, Brune et al. (2016) suggested that a systematic increase in divergence rate has occurred along various passive margins during rifting, and importantly, often $>10$ Myr prior to break-up. The authors linked this increase in divergence rate to the necking of the lithosphere, which weakens the crust, allowing the assumed constant forces that drive rifting to accelerate. However, a rift may still fail to fully break apart the continental lithosphere, even after attaining the necking stage (e.g. the North Sea Rift, Erratt et al., 1999), which would imply a decrease in divergence rates as the rift system wanes. It is known that divergence rates affect rift style (i.e. wide vs. narrow rifting, e.g. Brun, 1999; Zwaan et al., 2019), but to our knowledge only few modellers have explored the effects of changing divergence rates in their models. Brun and Tron (1993) and Naliboff et al. (2017) showed that increasing the divergence rate in a rift system can shift the deformation style from distributed to localised. However, these studies did not include the 3D effects of weaknesses in different parts of the lithosphere. Based on the single-phase rifting models by Zwaan et al. (2021a), we should expect an important effect of divergence rate 
changes on the localisation of deformation along these different weaknesses.

As such, we identify two end-member parameters that are generally considered to strongly affect rift evolution: (1) structural inheritance in the continental lithosphere, and (2) rifting kinematics (i.e. the direction, and rate, of divergence during one or more rifting phases). This amounts to comparing the impact of internal ('passive') geological parameters versus external ('dynamic') plate tectonic factors. In order to assess the relative importance of these internal and external factors, we completed a series of brittle-viscous analogue models. In these models we first simulated the general impact of different types and orientations of inherited weaknesses in the crust and mantle during single-phase rift evolution; subsequently, we tested the effect of changing divergence velocities as well as changing divergence directions. The model results were compared to previous work, which enabled us to develop a general framework with the relative importance of various internal and external factors on rift evolution.

Our main findings are that although crustal and mantle weaknesses can significantly affect the surface expression of rift systems, the principle factor governing rifting, and the localisation of deformation along such weaknesses, is the degree of coupling between the upper crust and upper mantle that is determined by the relative strength of the lower crust. This lower crustal strength itself is strongly affected by (changing) divergence rates, as well as the thickness and rheology of the lower crust. By contrast, changes in divergence directions over time only have a minor impact on the morphology of rift systems; older structures, if sufficiently developed, will likely reactivate so new structural orientations cannot readily develop. A further important observation is that various tectonic histories may lead to very similar structural arrangements, suggesting that detailed knowledge of fault activity and depocenter distribution over time is of paramount importance to unravel the true sequence of tectonic events. These insights also provide a good motivation to revisit the tectonic interpretation of natural examples (e.g. the North Sea).

\section{2 | METHODS}

\section{1 | Materials}

We applied brittle and viscous materials to simulate the continental crust (Figure 1a,b, Table 1). A $3 \mathrm{~cm}$ thick layer of fine quartz sand (ø $60-250 \mu \mathrm{m})$ was used to reproduce a $22.5 \mathrm{~km}$ thick brittle upper crust. The sand has an internal friction angle of $36.1^{\circ}$ (Zwaan, Schreurs, Gentzmann, et al., 2018), and a density of $1560 \mathrm{~kg} / \mathrm{m}^{3}$ when sieved from a height of ca. $30 \mathrm{~cm}$ (Klinkmüller et al., 2016). The sand was sieved onto a $1 \mathrm{~cm}$ thick basal viscous layer consisting of a mixture of Polydimethylsiloxane (PDMS) and corundum sand, which represented a $7.5 \mathrm{~km}$ thick ductile lower crust. The density of this mixture was $1600 \mathrm{~kg} / \mathrm{m}^{3}$ and the material had a near-Newtonian rheology, with a viscosity of ca. $1.5 \times 10^{5}$ Pa s (Zwaan, Schreurs, Ritter, et al., 2018).

\section{2 | General experimental set-up}

The general set-up of our models was based on the experimental set-up applied by Zwaan et al. (2021a, Figure 1). It involved a mobile base plate, attached to a mobile sidewall, the motion of which could be controlled by precise computer-guided motors. By operating these motors, the sidewall and the attached base plate could move both outward and sideward at different velocities, allowing us to implement different divergence directions and divergence rates (Figure 1c,d). Note that the deformation we applied was asymmetric (Figure 1, Allemand \& Brun, 1991).

Moving the sidewall and base plate created a velocity discontinuity (VD) along the edge of the mobile base plate. This VD has often been used to represent a weakness or fault/shear zone in the strong lithospheric mantle (e.g. Bonini et al., 1997; Brun \& Tron, 1993; Keep \& McClay, 1997; Michon \& Merle, 2000; Tron \& Brun, 1991; Zwaan et al., 2019, 2021a; Figure 1a,b). Applying different plate geometries and thus different VD orientations allowed us to test different mantle weakness orientations with respect to the general divergence direction, as defined by angle $\theta_{\mathrm{VD}}$ (Figure 1c,d).

In addition to these mantle weaknesses represented by the VD, we applied linear upper crustal weaknesses in the form of viscous seeds (Figure 1a,b,e,f) on top of the basal viscous layer. These seeds were semicircular bars $(\varnothing 5 \mathrm{~mm})$ made of the same viscous material as used for the lower crustal layer. Above these seeds the brittle sand layer was locally thinner, causing a $44 \%$ weakening of the brittle layer (Zwaan et al., 2021a), leading to the localisation of faulting (e.g. Le Calvez \& Vendeville, 2002; Molnar et al., 2018, 2020; Zwaan et al., 2016; Zwaan, Schreurs, \& Rosenau, 2020). It may be noted that different types of weaknesses with less impact on the strength of the modelled upper crustal layer could be used (e.g. thinner seeds, or pre-cut faults, Osagiede et al., 2021; Zwaan et al., 2021a), but we aimed to highlight the influence of such crustal weaknesses in this study and chose to simulate relatively significant weaknesses in the upper crust. Similar to the VD, we also applied different orientations for these simulated crustal weaknesses, defined as angle $\theta_{\mathrm{S}}($ Figure 1e,f). 


\section{D cut-out sketch of model set-up}

(a)

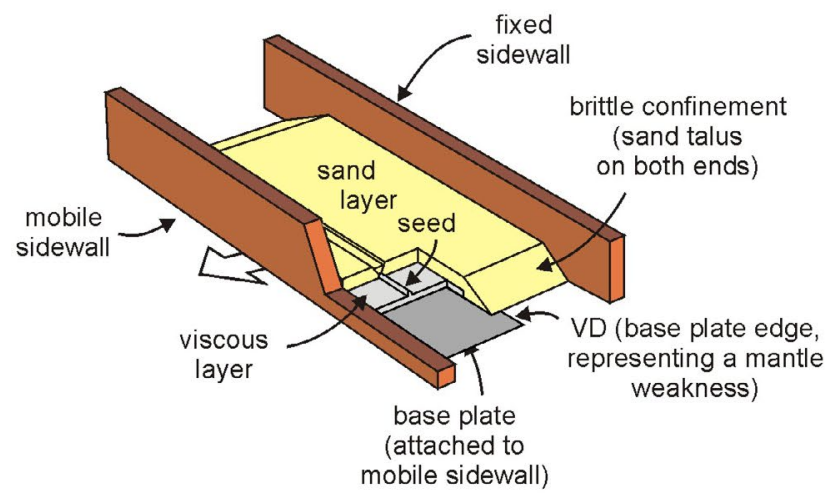

(b)

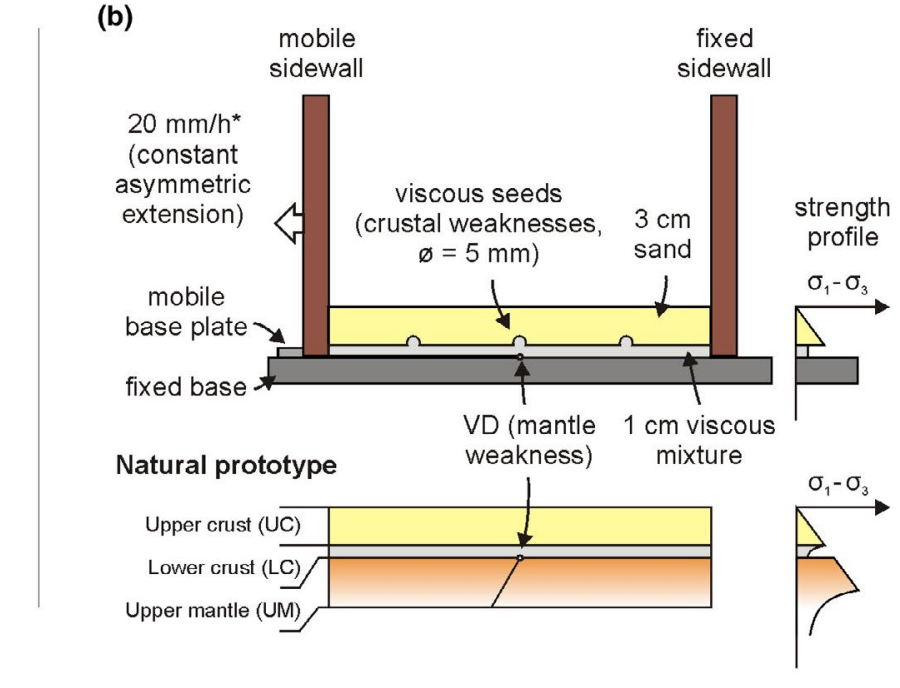

\section{Section view of model set-up}

\section{Model set-up, base plate (VD) geometries and divergence directions (top view)}

(c)

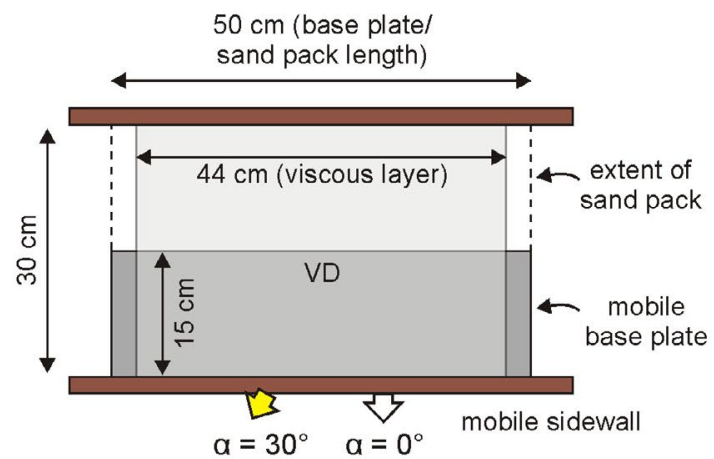

(d)

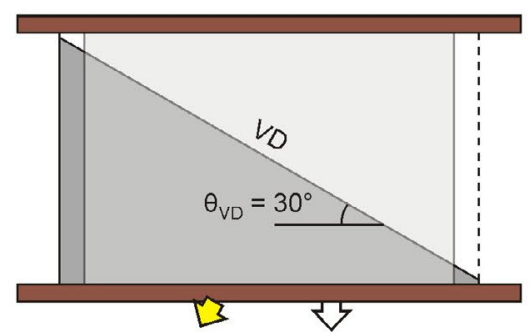

\section{Simulated crustal weakness (seed) geometries (top view)}

(e)

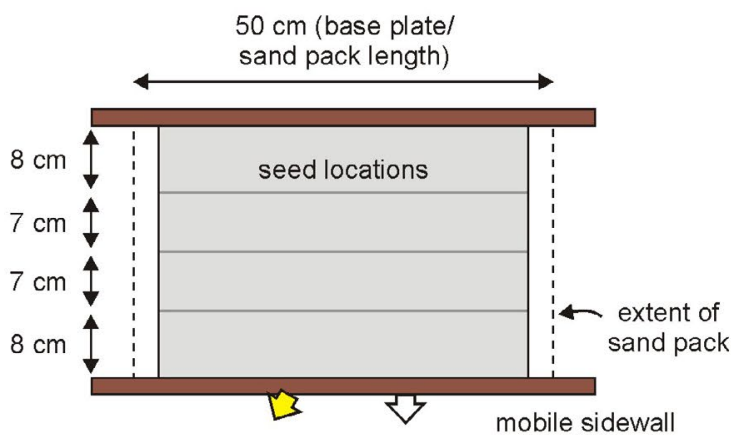

(f)

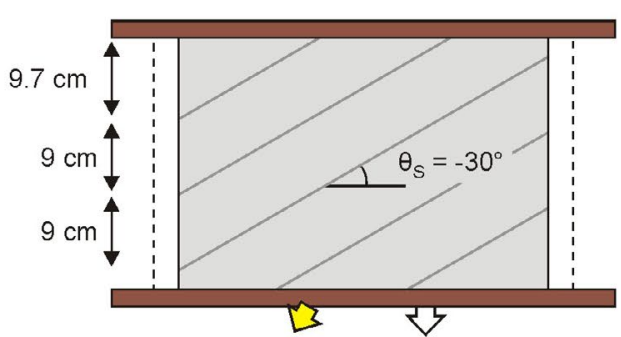

F I G U RE 1 Model set-up. (a) 3D sketch of general set-up. VD: velocity discontinuity representing a weakness or fault/shear zone in the strong upper mantle. (b) Section view depicting standard model layering and the viscous seeds, and the natural prototype this set-up represents. (c, d) Model dimensions, base plate geometries and definition of divergence direction (angle $\alpha$ ) are shown in map view. (c) Base plate configuration with VD parallel to model axis $\left(\theta_{\mathrm{VD}}=0^{\circ}\right)$. (d) Base plate configuration with VD $30^{\circ}$ oblique to model axis $\left(\theta_{\mathrm{VD}}=30^{\circ}\right)$. (e, f) Crustal weakness geometries at the top of the viscous layer, shown in map view. (e) Model axis-parallel crustal weaknesses $\left(\theta_{\mathrm{S}}=0^{\circ}\right)$. (f) Crustal weaknesses $30^{\circ}$ oblique to the model axis $\left(\theta_{\mathrm{S}}=-30^{\circ}\right)$. ${ }^{*} 20 \mathrm{~mm} / \mathrm{h}$ was the reference divergence rate (see Table 2). Modified after Zwaan et al. (2021a)

\section{3 | Model parameters}

We present the results of a total of 30 models from five experimental series containing six models each (Table 2).
The models in Series A served to establish a set of reference results for subsequent comparison with the multiphase rifting models from Series B-E. In the six reference models of Series A we tested the influence of two VD orientations 
TA B L E 1 Model materials

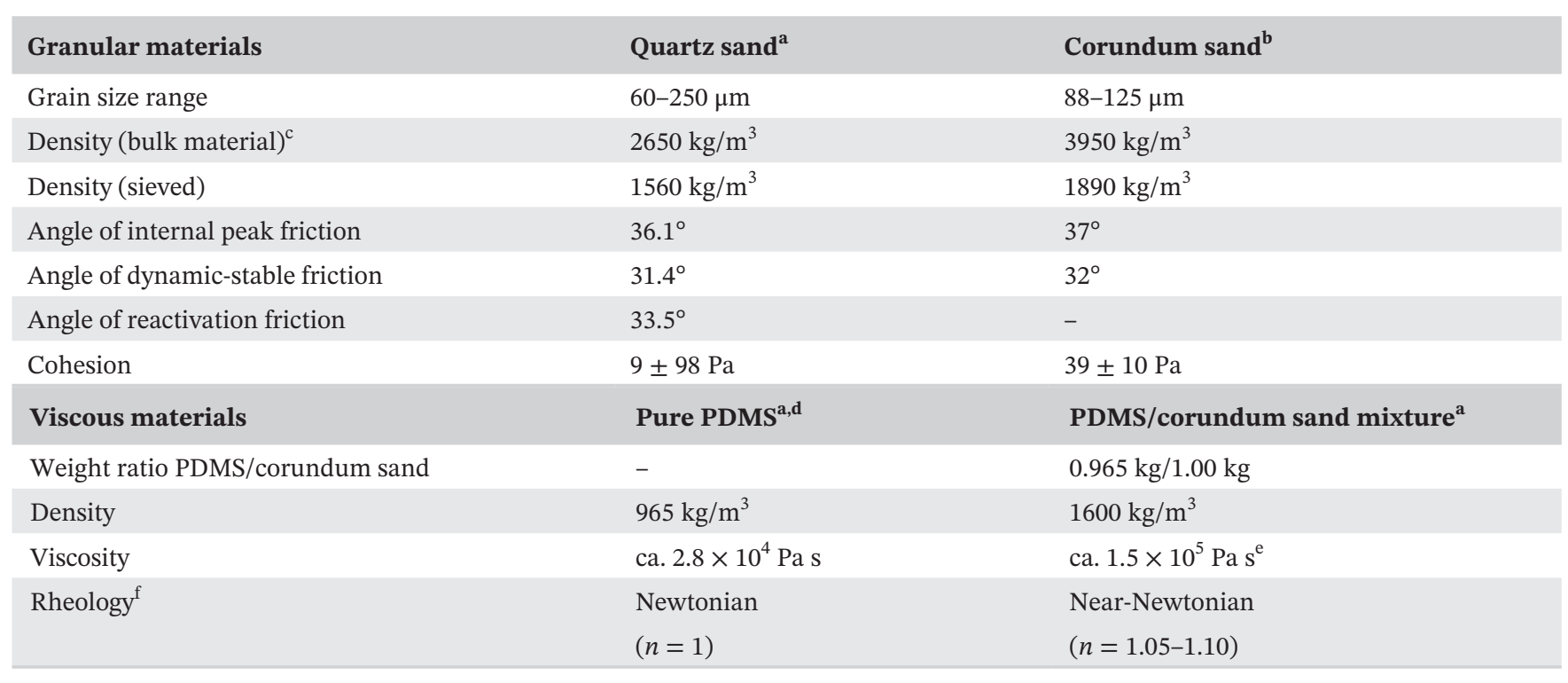

${ }^{a}$ Quartz sand, PDMS and viscous mixture characteristics after Zwaan et al. (2016), Zwaan, Schreurs, Gentzmann, et al. (2018), Zwaan, Schreurs, Ritter, et al. (2018).

${ }^{\mathrm{b}}$ Corundum sand characteristics after Panien et al. (2006).

${ }^{\mathrm{c}}$ Specific densities after Carlo AG (2021).

${ }^{\mathrm{d}}$ Pure PDMS rheology after Rudolf et al. (2016).

${ }^{\mathrm{e}}$ Viscosity value holds for model strain rates $<10^{-4} \mathrm{~s}^{-1}$.

${ }^{\mathrm{f}}$ Power-law exponent $n$ (dimensionless) represents sensitivity to strain rate.

$\left(\theta_{\mathrm{VD}}=0^{\circ}\right.$ and $\left.30^{\circ}\right)$, as well as various seed configurations (no seeds, $\theta_{\mathrm{S}}=0^{\circ}$, or $-30^{\circ}$ ) under constant orthogonal rifting conditions (angle $\alpha=0^{\circ}$ ). The divergence rate was set to be $20 \mathrm{~mm} / \mathrm{h}$ over a period of $2.5 \mathrm{~h}$, resulting in a total of $50 \mathrm{~mm}$ of divergence.

In Series B and C we tested the effects of a multiphase orthogonal rifting history (angle $\alpha=0^{\circ}$ ) involving changes in divergence rate. The models in these series had the same six basic initial set-ups as those in Series A, but the models were split into two phases of $25 \mathrm{~mm}$ of divergence each, amounting to the same $50 \mathrm{~mm}$ of total divergence applied in Series A. The first phase in model Series B involved slow rifting $(10 \mathrm{~mm} / \mathrm{h})$, followed by a second phase of fast rifting $(100 \mathrm{~mm} / \mathrm{h})$, mimicking the abrupt increase in divergence rate that occurs when a rift system starts to neck (Brune et al., 2016). Conversely, the first phase in Series $C$ involved a fast rifting phase $(100 \mathrm{~mm} / \mathrm{h})$, followed by a subsequent phase of slow rifting $(10 \mathrm{~mm} / \mathrm{h})$. With this fast-to-slow divergence rate variation we aimed to simulate decreasing divergence rates in a waning rift system that failed to reach the break-up stage (e.g. after the peak of the early [Triassic] rifting phase in the North Sea, Claringbould et al., 2020).

Series D and E were intended to simulate changing divergence directions over time rather than changing divergence rates, as proposed for various rift systems around the world (e.g. Bonini et al., 1997; Chorowicz et al., 1999; Heron et al., 2019; Zwaan et al., 2020b, Zwaan, Corti, Sani, et al., 2020). The initial model set-ups of Series D and E were the same as those used for Series A-C, but rifting was split into two phases with different directions. In Series D, initial rifting was orthogonal $\left(\alpha=0^{\circ}\right)$, followed by a second phase of oblique rifting $\left(\alpha=30^{\circ}\right)$ (as for instance reported for many rift systems around the globe, Brune et al., 2018). The models in Series E followed the inverse sequence: initial oblique rifting was followed by orthogonal rifting (e.g. proposed for the North Sea Central Graben, Erratt et al., 1999). In both series, the divergence rate was kept the same as in the reference models $(20 \mathrm{~mm} / \mathrm{h})$. Each phase involved $25 \mathrm{~mm}$ of stretching in the direction of divergence, for a total of $50 \mathrm{~mm}$ of divergence (so that overall stretching in the model is ca. $17 \%$, i.e. $\beta=$ ca. 1.2 ).

Note that several of the 30 model set-ups presented in this work were run multiple times with very similar results indicating good reproducibility. A complete dataset including the results obtained from all extra models can be found in the supplementary material (Zwaan et al., 2021b).

\section{4 | Analysis techniques}

The surface evolution of all models was monitored by means of time-lapse photography. A Nikon D200 (10 MP) camera provided map view images, and two obliquely oriented Nikon D810 (36.3 MP) cameras on both sides of the centrally mounted Nikon D200 allowed for a stereoscopic 
TABLE 2 Overview of model parameters

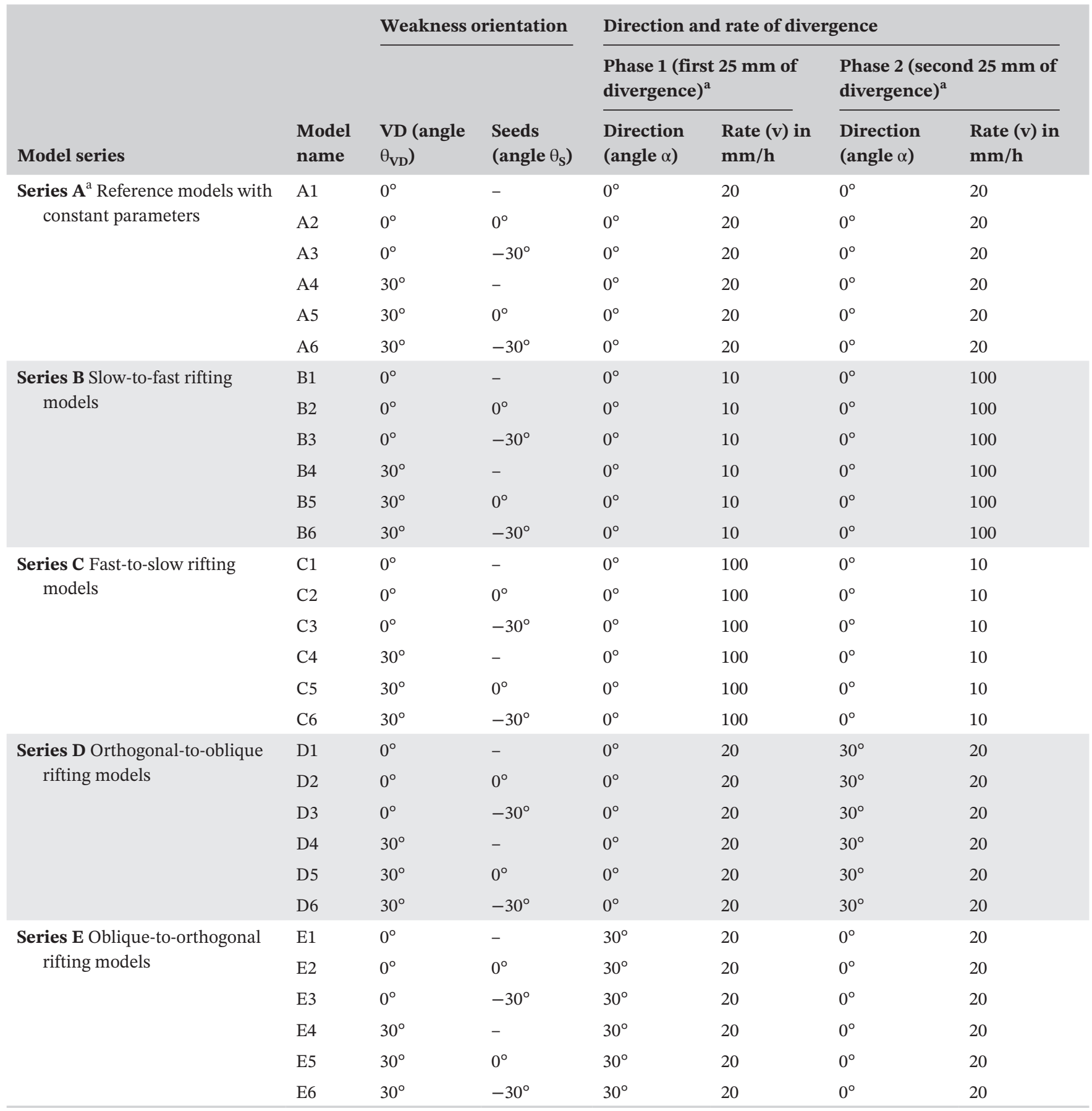

${ }^{\mathrm{a}} \mathrm{Series}$ A models were run continuously for $50 \mathrm{~mm}$ total divergence without change in parameters, hence in these models, phase 2 was simply a direct continuation of phase 1 .

view of the model. These cameras were all linked to a central computer and simultaneous remote-controlled pictures were taken every minute (after every $1 / 3 \mathrm{~mm}$ of divergence when $v=20 \mathrm{~mm} / \mathrm{h}$, after each $1 / 6 \mathrm{~mm}$ of divergence when $v=10 \mathrm{~mm} / \mathrm{h}$ rifting models, and after $5 / 3 \mathrm{~mm}$ of divergence when $v=100 \mathrm{~mm} / \mathrm{h}$ ). As these original time-lapse intervals represent different amounts of divergence, we used $5 \mathrm{~mm}$ divergence intervals for model analysis instead, which allowed for direct and systematic comparison of surface deformation between all models. We applied a $4 \times 4 \mathrm{~cm}$ grid of thin $<1 \mathrm{~mm}$ thick corundum sand on the model surface for visual assessment of horizontal displacements.

Next to providing a general visual impression of surface model evolution, these photographs also allowed a more detailed analysis and quantification of model surface deformation through means of Particle Image Velocimetry (PIV) techniques (e.g. Adam et al., 2005; Boutelier et al., 
2019, and references therein). This PIV analysis was done through a comparison of the high-resolution Nikon D810 time-lapse pictures in LaVision DaVis 10.2 PIV software (after correcting for image warping due to the obliquity of the images by systematically adopting the back-warping procedure applied to a reference plate of known dimensions). This software allowed us to extract horizontal displacements over time. These horizontal displacement data were subsequently used to create maps of the incremental maximum normal strain (i.e. the maximum extensional strain along the longest axis of the strain ellipse in map view, extracted at increments of $5 \mathrm{~mm}$ of divergence), which we took as a proxy to trace active deformation in the model over time. Using the maximum normal strain has the advantage that the strain is not simply plotted along either the $x$ - or $y$-axis of the top view images, but in the direction of the maximum strain, providing a more complete impression of normal fault activity. It has to be noted that even though some of the models did produce a degree of strike-slip movement as shown by the deformed surface grid, we did not directly analyse shear strain along the faults; all model structures were clearly normal faultdominated so that the maximum normal strain plots provide a sufficiently complete impression of model deformation for the purposes of this study.

In addition to the PIV-based strain analysis, we used the pairs of synchronous oblique high-quality Nikon D810 time-lapse photographs to reconstruct model topography in great detail. Fixed markers with known coordinates served to geo-reference the pictures in Agisoft PhotoScan photogrammetry software, yielding digital elevation models (DEMs). These DEMs allowed the visualisation of topographic changes, notably rift basin generation over time, which could be directly compared to the PIV results for a more complete understanding of model evolution.

\section{5 | Scaling}

Standard model scaling procedures served to ensure that laboratory experiments adequately represent the natural prototype. Since the rheology of brittle materials is strain rate-independent, the angle of internal friction of our sand was the main concern for scaling purposes. This angle $\left(36.1^{\circ}\right)$ is very similar to values found in upper crustal rocks $\left(31^{\circ}-38^{\circ}\right.$, Byerlee, 1978 , Table 3$)$. Scaling viscous materials is more complex than brittle materials since their strain rate-dependent rheology needs to be considered. With the stress ratio between model and nature $\left(\sigma^{*}\right.$, convention: $\left.\sigma^{*}=\sigma_{\text {model }} / \sigma_{\text {nature }}\right): \sigma^{*}=\rho^{*} h^{*} g^{*}$, where $\rho^{*}, h^{*}$ and $g^{*}$ are density, length and gravity ratios, respectively (Hubbert, 1937; Ramberg, 1981) and the viscosity ratio $\left(\eta^{*}\right)$ we can acquire the strain rate ratio $\dot{\varepsilon}^{*}$ (Weijermars \&
Schmeling, 1986): $\dot{\varepsilon}^{*}=\sigma^{*} / \eta^{*}$. The strain rate ratio subsequently allows us to derive the velocity and time ratios $\left(v^{*}\right.$ and $\left.t^{*}\right): \dot{\varepsilon}^{*}=v^{*} / h^{*}=1 / t^{*}$. Adopting a relatively high lower crustal viscosity of ca. $5 \times 10^{21} \mathrm{~Pa}$ s that may be typical for early magma-poor rift systems, e.g. Buck, (1991), one hour in our models scales up to ca. $3 \mathrm{Myr}$ in nature, and our reference divergence rate of $20 \mathrm{~mm} / \mathrm{h}$ translates to ca. $5 \mathrm{~mm} / \mathrm{yr}$. Our slow divergence rates $(10 \mathrm{~mm} / \mathrm{h})$ then translate to ca. $2.5 \mathrm{~mm} / \mathrm{y}$, and fast rifting $(100 \mathrm{~mm} / \mathrm{h})$ to ca. $25 \mathrm{~mm} / \mathrm{yr}$. These slow divergence rates are very similar to typical rift divergence rates in continental rifts (e.g. Saria et al., 2014), whereas the scaled fast divergence rates were in accordance with the accelerated divergence rates reported by Brune et al. (2016). An overview of scaling parameters is provided in Table 3.

In addition, we examined the dynamic similarity of the model and the natural example. It is possible to derive the dynamic similarity between the brittle model layer and its upper crustal equivalent using the ratio $R_{\mathrm{S}}$ between the gravitational stress and the cohesive strength or cohesion $C$ (Mulugeta, 1988; Ramberg, 1981): $R_{\mathrm{S}}=$ gravitational stress/cohesive strength $=(\rho g h) / C$. Assuming a natural cohesion of $12 \mathrm{MPa}$ for upper crustal rocks, together with a $9 \mathrm{~Pa}$ cohesion in the sand, we found

TABLE 3 Scaling parameters

\begin{tabular}{|c|c|c|}
\hline & Model & Nature \\
\hline \multicolumn{3}{|l|}{ General parameters } \\
\hline $\begin{array}{l}\text { Gravitational } \\
\quad \text { acceleration (g) }\end{array}$ & $9.81 \mathrm{~m} / \mathrm{s}^{2}$ & $9.81 \mathrm{~m} / \mathrm{s}^{2}$ \\
\hline Divergence rate (v) & $5.6 \times 10^{-6} \mathrm{~m} / \mathrm{s}^{\mathrm{a}}$ & $1.6 \times 10^{-10} \mathrm{~m} / \mathrm{s}$ \\
\hline \multicolumn{3}{|l|}{ Brittle layer } \\
\hline Material & Quartz sand & Upper crust \\
\hline $\begin{array}{l}\text { Peak internal friction } \\
\text { angle }(\varphi)\end{array}$ & $36.1^{\circ}$ & $30^{\circ}-38^{\circ}$ \\
\hline Thickness (h) & $3 \times 10^{-2} \mathrm{~m}$ & $2.25 \times 10^{4} \mathrm{~m}$ \\
\hline Density $(\rho)$ & $1560 \mathrm{~kg} / \mathrm{m}^{3}$ & $2800 \mathrm{~kg} / \mathrm{m}^{3}$ \\
\hline Cohesion (C) & $9 \mathrm{~Pa}$ & $1.2 \times 10^{7} \mathrm{~Pa}$ \\
\hline \multicolumn{3}{|l|}{ Viscous/ductile layer } \\
\hline Material & $\begin{array}{l}\text { PDMS/ } \\
\text { corundum } \\
\text { sand mixture }\end{array}$ & Lower crust \\
\hline Thickness (h) & $1 \times 10^{-2} \mathrm{~m}$ & $7.5 \times 10^{4} \mathrm{~m}$ \\
\hline Density $(\rho)$ & $1600 \mathrm{~kg} / \mathrm{m}^{3}$ & $2900 \mathrm{~kg} / \mathrm{m}^{3}$ \\
\hline Viscosity ( $\eta)$ & $1.5 \times 10^{5} \mathrm{~Pa} \mathrm{~s}$ & $5 \times 10^{21} \mathrm{~Pa} \mathrm{~s}$ \\
\hline \multicolumn{3}{|l|}{ Dynamic scaling values } \\
\hline Brittle stress ratio $\left(R_{\mathrm{s}}\right)$ & 51 & 51 \\
\hline Ramberg number $\left(R_{\mathrm{m}}\right)$ & 17 & 17 \\
\hline
\end{tabular}

${ }^{\mathrm{a}}$ Divergence rate in the reference models (Series A, $v=20 \mathrm{~mm} / \mathrm{h}$, see Table 2). 
a $R_{\mathrm{S}}$ of 51 for both model and nature. Although this natural cohesion value of $12 \mathrm{MPa}$ is slightly lower than cohesions obtained from rock deformation tests (e.g. Handin, 1969; Jaeger \& Cook, 1976; Twiss \& Moore, 1992), we considered it quite acceptable since the strength of the lithosphere in nature has generally decreased during subsequent deformation phases prior to present-day deformation. The Ramberg number $R_{\mathrm{m}}$ applies for dynamic similarity scaling of viscous materials (Weijermars \& Schmeling, 1986): $R_{\mathrm{m}}=$ gravitational stress/viscous strength $=\left(\rho g h^{2}\right) /(\eta v)$, and we found a value of 17 for both the viscous mixture and its lower crustal equivalent in nature. Since both the $R_{\mathrm{S}}$ and $R_{\mathrm{m}}$ values of our models were practically the same as in their natural equivalent, we considered our models properly scaled for simulating continental rifting.

\section{RESULTS}

We present the results of our model analysis in a series of overview figures (Figures 2-6). These figures show the incremental maximum normal strain as derived from PIV analysis over a divergence increment of $5 \mathrm{~mm}$ at the start and end of each deformation phase. The model surface topography at the end of each deformation phase is included as well. We first discuss the reference models from Series $\mathrm{A}$, and then the multiphase rifting models from Series B-E.

\section{1 | Series A-Reference models}

The results from our Series A models with a constant divergence direction $\left(\alpha=0^{\circ}\right)$ and a constant divergence rate of $20 \mathrm{~mm} / \mathrm{h}$ provide a reference framework for the subsequent analysis of multiphase rifting models (Figure 2).

\subsection{1 | Model axis-parallel VD Models A1-A3}

Model A1, involving an axis-parallel VD set-up $\left(\theta_{\mathrm{VD}}=0^{\circ}\right)$ without seeds, developed two deformation zones on both sides of the VD during the initial stages of the experimental run (Figure 2a $\mathrm{a}_{\mathrm{I}}$ ). Subsequently, strain localised along normal faults and a narrow double graben system developed (Figure $2 \mathrm{a}_{\text {IIIIII }}$ ). As stretching continued, the rift structure grew wider due to the start of new faulting on the moving base plate, leading to the formation of an additional graben, whereas fault activity on the opposite side of the graben diminished notably (Figure $2 \mathrm{a}_{\mathrm{IV}-\mathrm{VI}}$ ). Some boundary effects are visible on both sides of the model.
Adding model-axis parallel seeds $\left(\theta_{\mathrm{S}}=0^{\circ}\right)$ in Model A2 considerably modified the central double graben structure seen in Model A1 by diverting deformation away from the VD (Figure 2a,b). Initial deformation strongly localised along the outermost seeds, forming through-going grabens, in contrast to the various grabens developing in the central part of the model (Figure $2 \mathrm{~b}_{\text {I-III }}$ ). This structural arrangement was established early on and remained in place during subsequent stretching (Figure $2 \mathrm{~b}_{\mathrm{IV}-\mathrm{VI}}$ ), but no clear migration of deformation onto the moving base plate as in Model A1 was observed (Figure 2a,b). Some boundary effects occurred on both sides of the model.

Applying oblique seeds $\left(\theta_{\mathrm{S}}=-30^{\circ}\right)$ in Model A3 also disrupted the central rift structure observed in Model A1, but in a different fashion than in Model A2 (Figure 2ac). Whereas the initial stages of Model A3 formed similar deformation zones on both sides of the VD as in Model A1 (Figure $2 \mathrm{a}_{\mathrm{I}}, \mathrm{c}_{\mathrm{I}}$ ), the oblique seeds localised deformation early on, leading to the establishment of a series of oblique grabens (Figure $2 \mathrm{c}_{\text {I-III }}$ ). Meanwhile, the deformation zones from the earlier stages of Model A3 developed into a series of double grabens that were interrupted and segmented by the seed-induced graben structures (Figure $\left.2 \mathrm{c}_{\text {I-III }}\right)$. Like in Model A2, this structural arrangement was formed early on and remained stable during the following $25 \mathrm{~mm}$ of stretching, although we did observe a slight migration of strain onto the moving base plate over time, and the formation of more pronounced boundary effects (grabens) along the lower sidewall (Figure $2 \mathrm{c}_{\mathrm{IV}-\mathrm{VI}}$ ).

\subsection{2 | Oblique VD Models A4-A6}

The use of an oblique VD in Model A4 $\left(\theta_{\mathrm{VD}}=30^{\circ}\right.$, without seeds) led to the development of a very different structure than that observed in its equivalent with a model axis-parallel (Model A1, Figure 2a,d). Although Model A4 did form initial deformation zones along the VD (similar to those in Model A1, Figure $2 \mathrm{a}_{\mathrm{I}}, \mathrm{d}_{\mathrm{I}}$ ), these developed into two series of en echelon grabens on both sides of the oblique VD, instead of a through-going rift structure with long normal faults as observed in Model A1 (Figure 2a,d). As deformation continued, the oblique rift structure grew significantly wider, and a slight shift of strain onto the moving base plate was observed (Figure $2 \mathrm{~d}_{\mathrm{IV}-\mathrm{VI}}$ ).

Similar to Models A2 and A3, the introduction of seeds in Models A5 and A6 with an oblique VD strongly affected the evolution of our rift structures (Figure $2 b, c, e, f)$. The results from Model A5 show how the presence of rift axis-parallel seeds $\left(\theta_{\mathrm{S}}=0^{\circ}\right)$ almost completely overprinted the VDinduced structures; the initial double deformation zones along the VD formed early on, yet the seeds also localised deformation early on (Figure $2 \mathrm{e}_{\mathrm{I}}$ ). The grabens developing 


\section{Series A - Reference models}
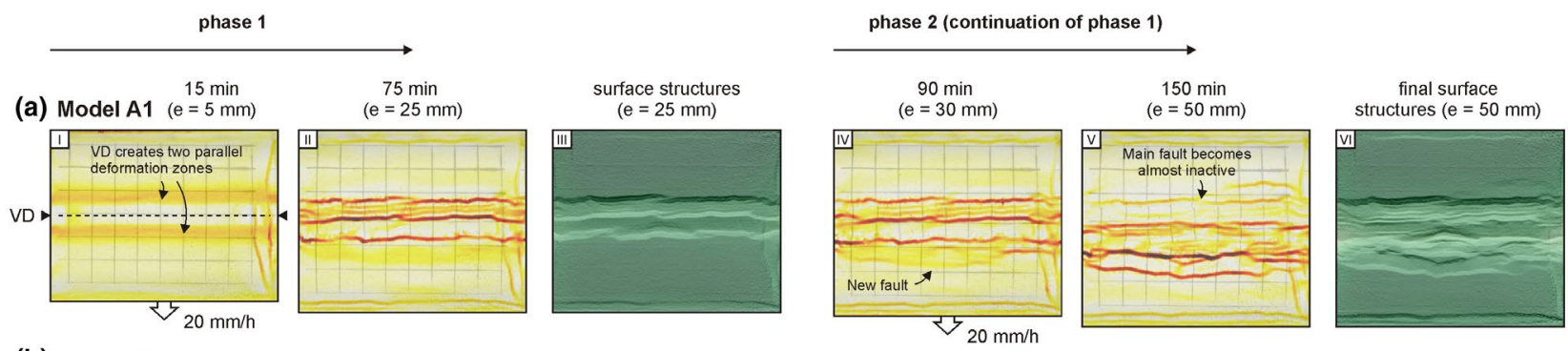

(b) Model A2
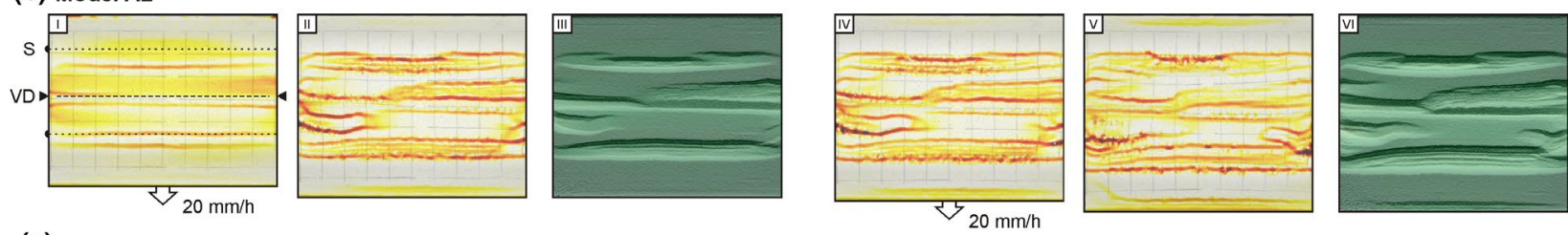

(c) Model A3
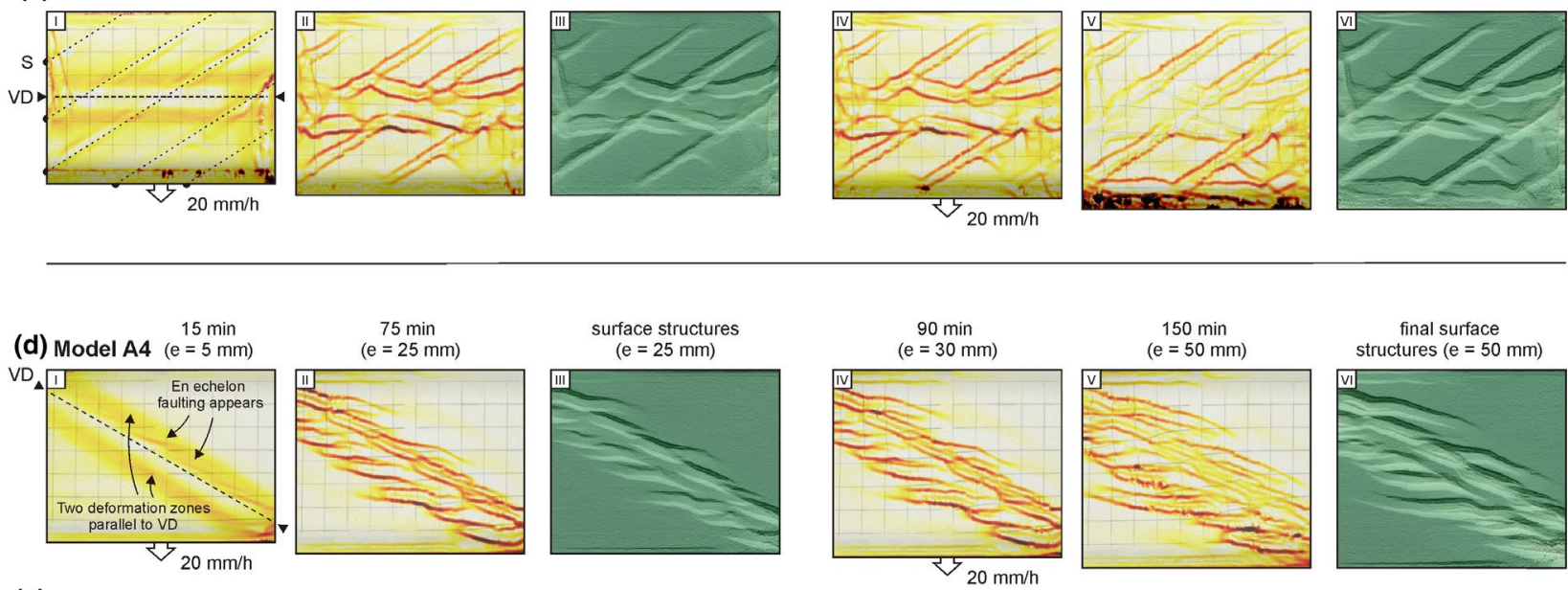

(e) Model A5
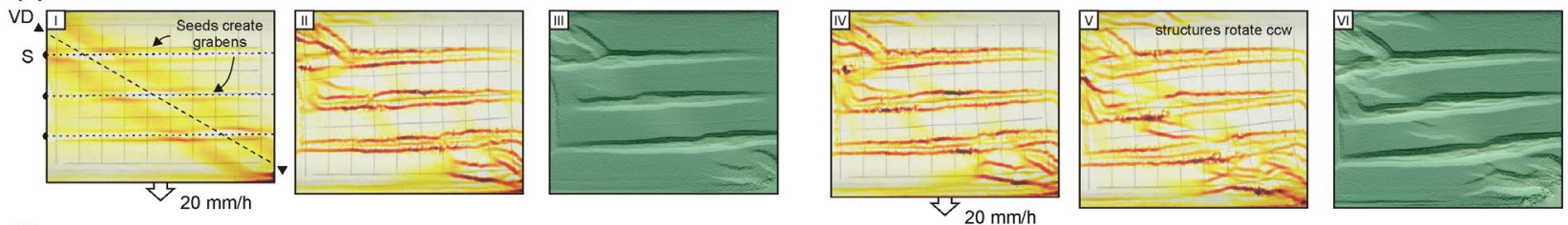

\section{(f) Model A6}
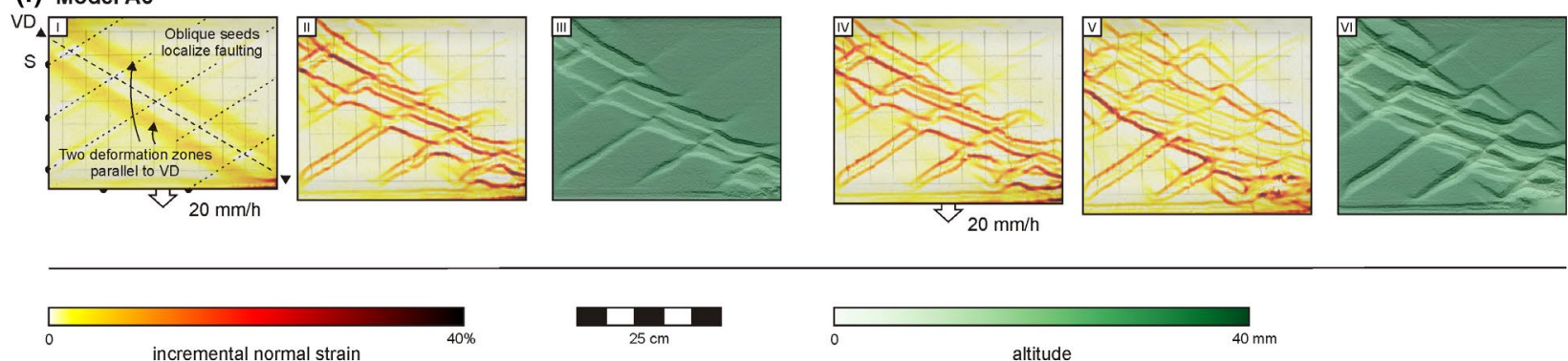

$25 \mathrm{~cm}$

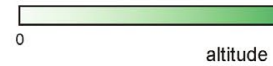

F I G U RE 2 Model PIV and topography analysis result from reference Series A, with constant orthogonal rifting $\left(\alpha=0^{\circ}\right)$ and a constant divergence rate of $20 \mathrm{~mm} / \mathrm{h}$. Divergence increments for PIV analysis were $5 \mathrm{~mm}$. S, seeds; VD, velocity discontinuity

along these seeds accommodated most of the subsequent deformation in Model A5 (Figure 2 $\mathrm{e}_{\mathrm{II}-\mathrm{VI}}$ ). In contrast to Model A5, the VD still had an important influence in Model A6 (Figure 2f) since the presence of $-30^{\circ}$ oblique seeds did not prevent the development of the dual VD-parallel deformation zones (Figure $2 \mathrm{e}_{\mathrm{I}}, \mathrm{f}_{\mathrm{I}}$ ). Yet, the early activation of these seeds did, in a similar fashion to Model A3, segment and interrupt the rift structure along the VD from an early 


\section{Series B - Slow-to-fast rifting models}

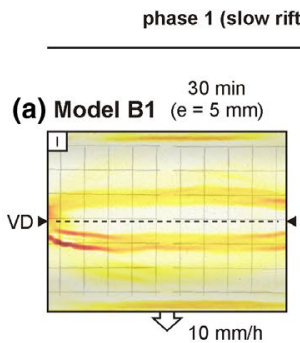

(b) Model B2
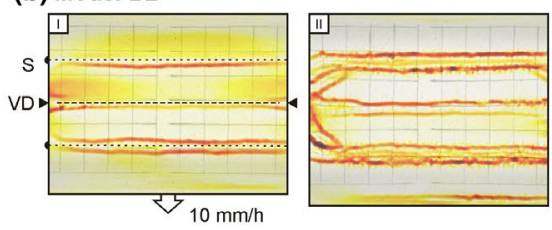

(c) Model B3
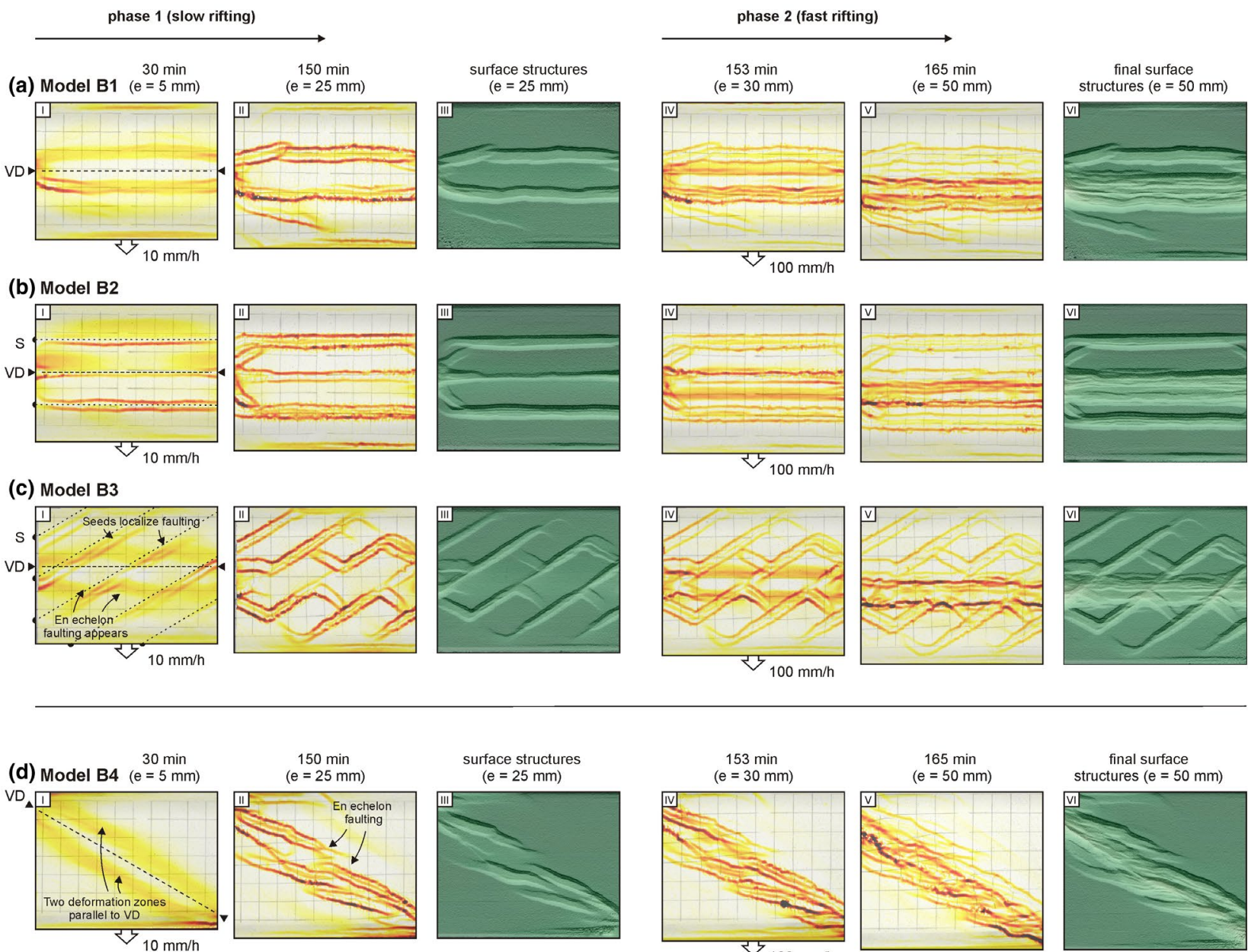

(e) Model B5
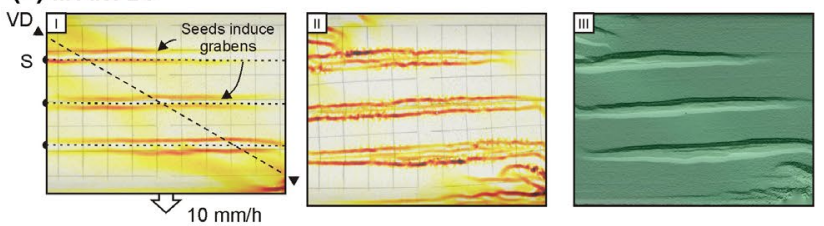

(f) Model B6
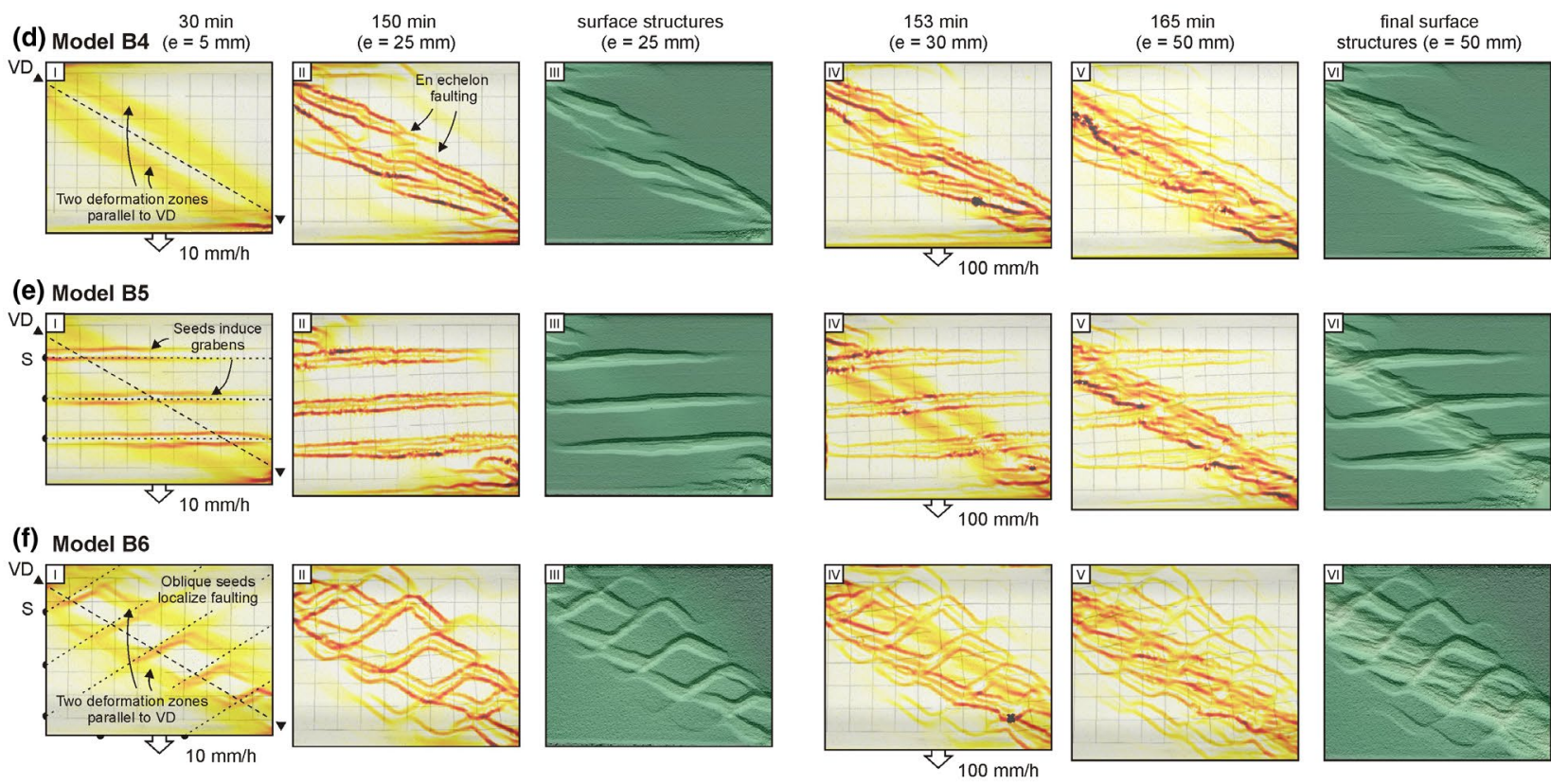

ltitude
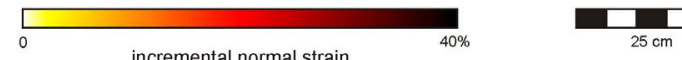

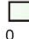
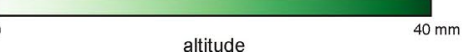

F I G U RE 3 Model PIV and topography analysis result from Series B involving a first phase of slow rifting (10 mm/h) followed by a second phase of fast rifting $(100 \mathrm{~mm} / \mathrm{h})$. The divergence direction was orthogonal during both phases $\left(\alpha=0^{\circ}\right)$. Divergence increments for PIV analysis were $5 \mathrm{~mm}$. S, seeds; VD, velocity discontinuity

stage on (Figure 2c, $\mathrm{f}_{\mathrm{II}, \mathrm{III}}$ ). During subsequent deformation, a complex distribution of oblique grabens developed, with an apparent migration of deformation onto the moving base plate (Figure $2 \mathrm{f}_{\text {IV-VI }}$ ).

\section{2 | Series B-Slow-to-fast rifting models}

Here we present the results from our series B models involving an initial phase of slow rifting $(10 \mathrm{~mm} / \mathrm{h})$, followed 
by a second phase of fast rifting $(100 \mathrm{~mm} / \mathrm{h})$ (Figure 3$)$. The divergence direction throughout the model runs was kept constant (angle $\alpha=0^{\circ}$ ).

\subsection{1 | Model axis-parallel VD Models B1-B3}

The results from Model B1 show how initial slow divergence rates affect an experiment with a model-parallel $\operatorname{VD}\left(\theta_{\mathrm{VD}}=0^{\circ}\right)$ and no seeds (Figure $\left.3 \mathrm{a}_{\mathrm{I}-\mathrm{III}}\right)$. The model developed similar deformation zones as those in reference Model A1 (Figure 2a $\mathrm{a}_{\mathrm{I}}$ ), but with a wider spacing in Model B1 (Figure $3 \mathrm{a}_{\mathrm{I}}$ ). As a result, the initial rift structure in Model B1 was wider than in reference Model A1, consisting of two separated grabens instead of a central rift zone (Figures $2 \mathrm{a}_{\mathrm{II}, \mathrm{III}}$ and $3 \mathrm{a}_{\mathrm{II}, \mathrm{III}}$ ). During the subsequent phase of fast rifting, the style of deformation changed considerably (Figure $3 \mathrm{a}_{\mathrm{IV}-\mathrm{VI}}$ ) as faulting became much more concentrated along the VD, leading to the overprinting of the initial broad rift structure by a narrow rift basin.

The divergence rate had a clear influence on the localisation of deformation along the seeds as well. During the initial slow rifting phase in Model B2, the rift axis-parallel seeds $\left(\theta_{\mathrm{S}}=0^{\circ}\right)$ localised rifting more readily than in reference Model A2, by forming a series of spaced-out grabens (Figures $2 \mathrm{~b}_{\mathrm{I}-\mathrm{III}}$ and $3 \mathrm{~b}_{\mathrm{I}-\mathrm{III}}$ ). And similar to Model B1, the subsequent fast rifting phase overprinted this wide rift structure with a narrow rift basin (Figure $3 \mathrm{a}_{\mathrm{IV}-\mathrm{VI}}, \mathrm{b}_{\mathrm{IV}-\mathrm{VI}}$ ). The same tendencies were observed in Model B3 with $-30^{\circ}$ oblique seeds: initially the seeds dominantly localised deformation, even though somewhat offset VD-parallel rift zones formed, which evolved into offset grabens similar to those observed in reference Model A3 (Figures $2 \mathrm{c}_{\mathrm{I}-\mathrm{III}}$ and $\left.3 \mathrm{c}_{\mathrm{I}-\mathrm{III}}\right)$. But the subsequent fast rifting phase in Model B3 caused an overprinting effect by the VD, creating a clearly defined central rift basin (Figure $3 \mathrm{c}_{\mathrm{IV}-\mathrm{VI}}$ ).

\subsection{2 | Oblique VD Models B4-B6}

The presence of a $30^{\circ}$ oblique VD in absence of seeds resulted in the development of initial VD-parallel diffuse deformation zones that later localised en echelon faulting during the first slow rifting phase in Model B4 (Figure $\left.3 \mathrm{~d}_{\text {I-III }}\right)$. The occurrence of these deformation zones was similar to those observed in reference Model A4, but the en echelon arrangement of the subsequent faults was much more parallel to the VD in Model B4 (Figure $3 \mathrm{~d}_{\text {I-III }}$ ). When applying fast divergence during the second phase, strain became mostly concentrated along the VD (Figure $3 \mathrm{~d}_{\mathrm{IV}-\mathrm{VI}}$ ).

As previously observed in Models A5 and A6, seeds tend to strongly localise deformation when initial divergence rates are (relatively) slow (Models B5 and B6. Figure $\left.3 \mathrm{e}_{\mathrm{I}-\mathrm{II}}, \mathrm{f}_{\mathrm{I}-\mathrm{III}}\right)$. In Model B5, we found that localisation of deformation along the model axis-parallel seeds $\left(\theta_{\mathrm{S}}=0^{\circ}\right)$ was even more pronounced than in Model A5, up to the point that the influence of the VD was negligible (Figures $2 \mathrm{e}_{\mathrm{I}-\mathrm{III}}$ and $\left.3 \mathrm{e}_{\mathrm{I}-\mathrm{III}}\right)$. In Model $\mathrm{B} 6$ the $-30^{\circ}$ oblique seedinduced grabens had a much greater influence on the rift structure than in Model A6, even though the VD in model B6 did localise initial deformation zones and caused the general structure to follow a $30^{\circ}$ oblique path (Figures $2 \mathrm{f}_{\mathrm{I}-\mathrm{III}}$ and $3 \mathrm{f}_{\mathrm{I}-\mathrm{III}}$ ). However, similar to Models B2 and B3 (Figure $3 \mathrm{~b}_{\mathrm{IV}-\mathrm{VI}}, \mathrm{c}_{\mathrm{IV}-\mathrm{VI}}$ ), the subsequent fast divergence in Models B5 and B6 strongly concentrated deformation, overprinting the structures formed during the initial slow phase with a highly localised rift basin along the VD (Figure $3 \mathrm{e}_{\mathrm{IV}-\mathrm{VI}}, \mathrm{f}_{\mathrm{IV}-\mathrm{I}}$ ).

\section{3 | Series C-Fast-to-slow rifting models}

In this section, we describe the results from our series $\mathrm{C}$ models with an initial phase of fast rifting $(100 \mathrm{~mm} / \mathrm{h})$, and a subsequent phase of slow rifting $(10 \mathrm{~mm} / \mathrm{h})$ (Figure 4). The divergence direction was constant during the experimental runs $\left(\right.$ angle $\alpha=0^{\circ}$ ).

\subsection{1 | Model axis-parallel VD Models C1-C3}

The results from the second, fast rifting phase in the models from Series B suggest that fast rifting localises deformation along the VD (Figure 3), and we found a similar effect in our Model C1 with a model-axis parallel VD and no seeds (Figure 4a). During the initial fast rifting phase in Model $\mathrm{C} 1$, the two deformation zones previously observed in reference Model A1 developed as well (Figures $2 \mathrm{a}_{\mathrm{I}}$ and $4 \mathrm{a}_{\mathrm{I}}$ ), but the subsequent (double) rift structure was clearly narrower (Figures $2 \mathrm{a}_{\text {II,III }}$ and $4 \mathrm{a}_{\mathrm{II}, \text { III }}$ ). In the following slow rifting phase, strain was, however, much more distributed than during the first phase, and the final rift structure became much wider than the initial narrow basin (Figure $4 \mathrm{a}_{\text {IV-VI }}$ ).

The same concentration of deformation during initial fast rifting was observed in Models $\mathrm{C} 2$ and $\mathrm{C} 3$ (Figure $\left.4 \mathrm{~b}_{\mathrm{I}-\mathrm{III}}, \mathrm{C}_{\mathrm{I}-\mathrm{III}}\right)$. In these models, most deformation was concentrated in the initial deformation zones along the VD that subsequently develop into a narrow rift basin, whereas the seeds localised only very limited faulting (Figure $\left.4 \mathrm{~b}_{\text {I-III }}, \mathrm{C}_{\text {I-III }}\right)$. Yet, as soon as the divergence rate dropped during the second phase, deformation became primarily concentrated along the seeds (Figure $4 \mathrm{~b}_{\mathrm{IV}-\mathrm{VI}}, \mathrm{c}_{\mathrm{IV}-\mathrm{VI}}$ ). Note how the final structures in Models $\mathrm{C} 1-\mathrm{C} 3$ are very similar to those observed in the equivalent Series B models (i.e. Models B1-B3, Figures 3 and 4). 


\section{Series C - Fast-to-slow rifting models}
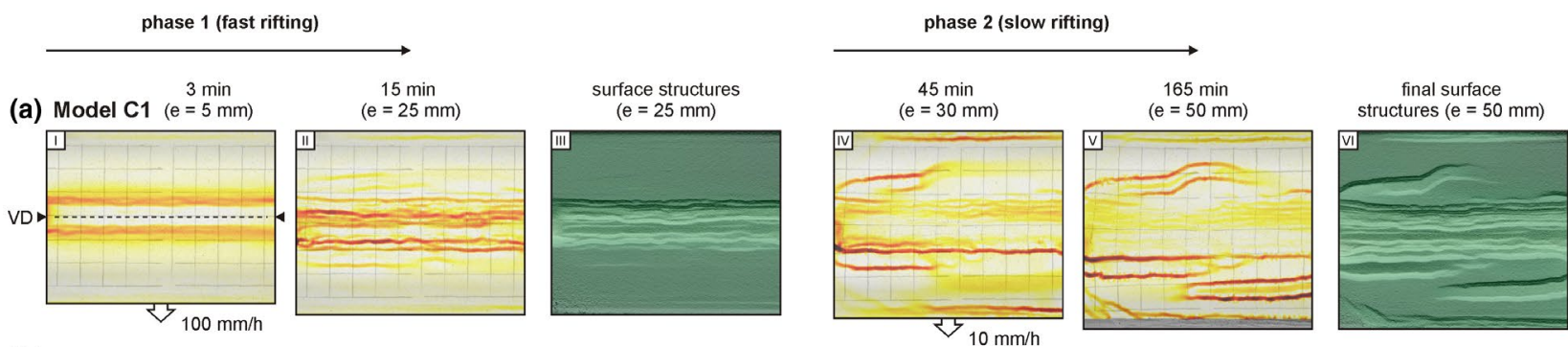

\section{(b) Model C2}
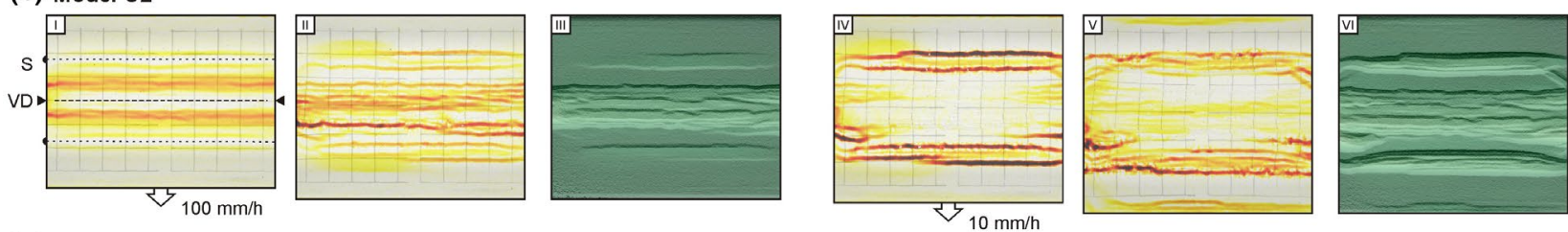

(c) Model C3
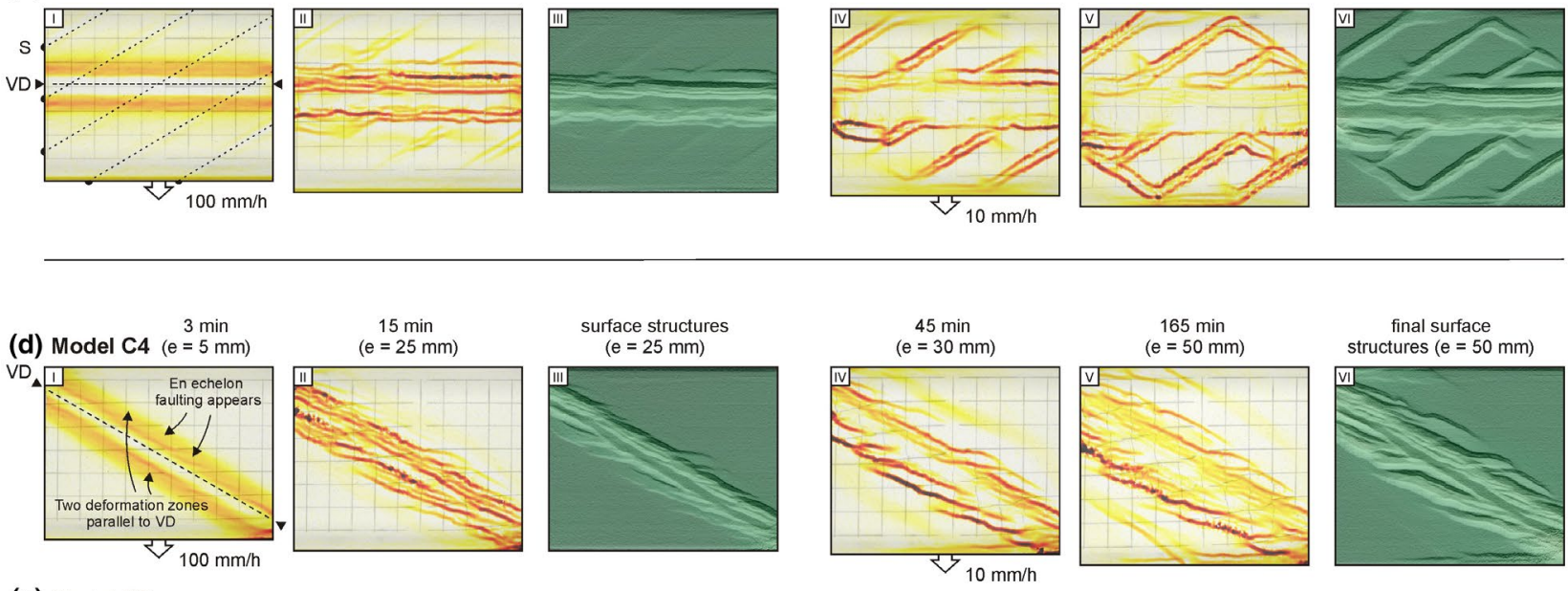

(e) Model C5
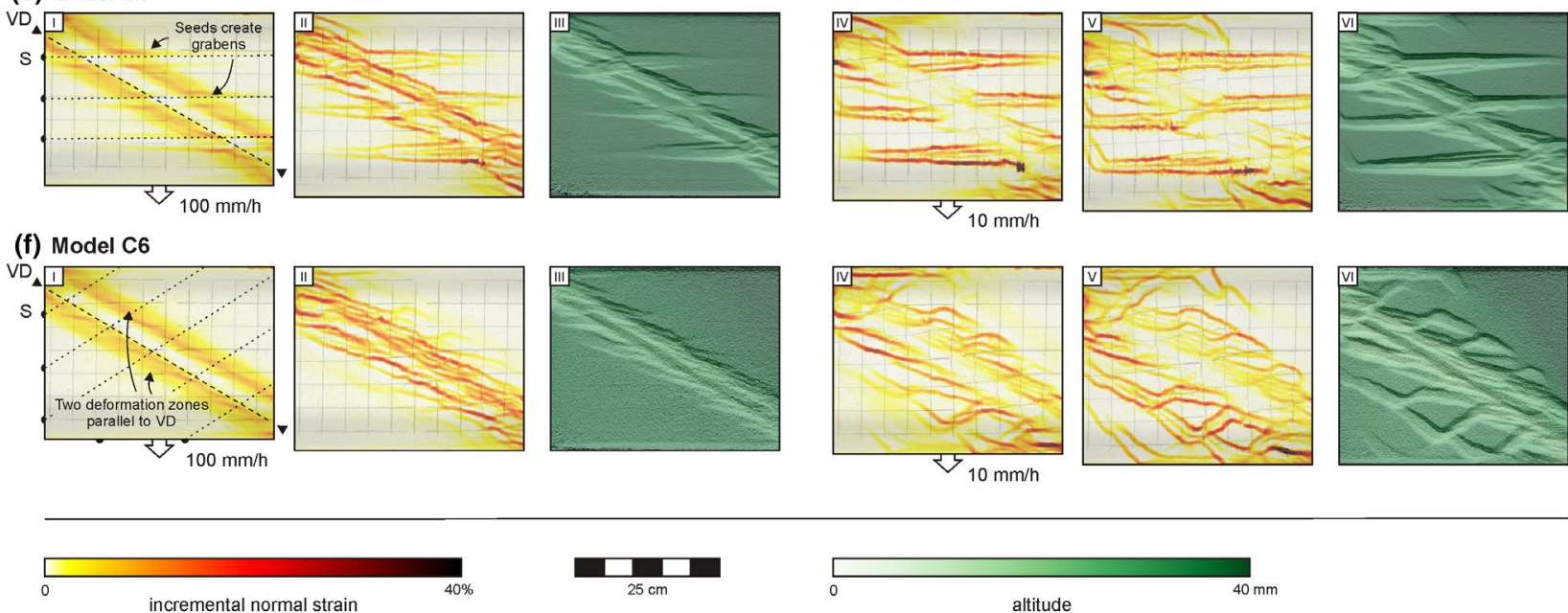

F I G U R E 4 Model PIV and topography analysis results from Series C involving a first phase of fast rifting (100 mm/h) followed by a second phase of slow rifting $(10 \mathrm{~mm} / \mathrm{h})$. The divergence direction was orthogonal during both phases $\left(\alpha=0^{\circ}\right)$. Divergence increments for PIV analysis were $5 \mathrm{~mm}$. S, seeds; VD, velocity discontinuity

\subsection{2 | Oblique VD Models C4-C6}

Models C4-C6 with a $30^{\circ}$ oblique VD showed very similar reactions to divergence rate as Models C1-C3 (Figure
4). Model C4, without seeds, formed deformation zones along the VD during the initial fast rifting phase, which resulted in a rift basin along the VD that was more concentrated than its counterpart in reference Model A4, as 
it largely lacked the en echelon arrangement of the latter (Figures $2 \mathrm{~d}_{\text {I-III }}$ and $4 \mathrm{~d}_{\text {I-III }}$ ). Yet, when exposed to slow rifting during the second model phase, deformation in Model $\mathrm{C} 4$ became much more distributed, as previously observed in Model C1 (Figure $4 \mathrm{a}_{\text {IV-VI }}, \mathrm{d}_{\mathrm{IV}-\mathrm{VI}}$ ).

The influence of the seeds in Models C5 and C6 was similarly modified by the changes in divergence rate as in Models C2 and C3 (Figure 4b,c,e,f). During the initial fast rifting phase in Models C5 and C6, deformation was strongly concentrated along the initial deformation zones and subsequent faults along VD, whereas the seeds showed barely any strain localisation (Figure $4 \mathrm{e}_{\mathrm{I}-\mathrm{III}}, \mathrm{f}_{\mathrm{I}-\mathrm{III}}$ ). This was in stark contrast to the dominant strain localisation along the seeds in the equivalent reference models (Models A5 and A6) and models with initial slow rifting (Models B5 and B6) (Figures 2e,f and 3e,f). But similar to Models C2 and C3 (Figure $4 \mathrm{~b}_{\mathrm{IV}-\mathrm{VI}}, \mathrm{c}_{\mathrm{IV}-\mathrm{VI}}$ ), the divergence rate decrease during the second phase in Models C5 and C6 caused a significant shift towards broader, more distributed deformation and localisation of deformation along the seeds (Figure $4 \mathrm{e}_{\mathrm{IV}-\mathrm{VI}}, \mathrm{f}_{\mathrm{IV}-\mathrm{VI}}$ ). Seed-related structures became more pronounced in Model C5, in which the seeds were parallel to the model axis, than in Model C6, which had oblique seeds (Figure $4 \mathrm{e}_{\mathrm{IV-VI}}, \mathrm{f}_{\mathrm{IV}-\mathrm{VI}}$ ). It is furthermore worth noting that also the final structures in these Series C models were very similar to the structures observed in the equivalent Series B models (see final topography shown in Figures 3 and 4).

\section{4 | Series D-Orthogonal-to-oblique rifting models}

Our Series D models included an initial phase orthogonal rifting $\left(\alpha=0^{\circ}\right)$, followed by a phase of oblique rifting $\left(\alpha=30^{\circ}\right)$ (Figure 5). The divergence rate was the same as in the reference models $(20 \mathrm{~mm} / \mathrm{h})$.

\subsection{1 $\quad$ Model axis-parallel VD Models D1-D3}

The boundary conditions in the early stages of Models D1-D3 with a model axis-parallel VD (Figure 5a-c) were the same as in reference Models A1-A3 (Figure $2 \mathrm{a}-\mathrm{c}$ ), and therefore the results were fairly similar. There are some minor differences in the timing of fault initiation (compare Model A1 with Model D1, Figures 2a and 5a) and the structures are not exactly the same (notably the extra graben in Model D1). Yet, the models provide a good match, which highlights the consistency of our model approach. As Models D1-D3 continued to develop during a second phase of $30^{\circ}$ oblique rifting, the overall graben arrangement did not deviate much from the one established during the first phase (Figure $5 \mathrm{a}-\mathrm{c}$ ), and as such the overall results from these models are in general very similar to the structures observed in the reference Models A1-A3 (Figures 2a-c and $5 \mathrm{a}-\mathrm{c})$.

\subsubsection{Oblique VD Models D4-D6}

Similar to Models D1-D3, the initial orthogonal rifting phase in Models D4-D6 with a $30^{\circ}$ oblique VD yielded very comparable results to reference Models A4-A6 (Figures $2 \mathrm{~d}-\mathrm{f}$ and $5 \mathrm{~d}-\mathrm{f}$ ). These models did largely reuse the structures established from the first phase during the second, $30^{\circ}$ oblique rifting phase. A small exception to the rule is the development of two grabens oriented subparallel to the VD in Model D4 (Figure 5e $\mathrm{e}_{\mathrm{IV}-\mathrm{VI}}$ ).

\section{5 | Series E-Oblique-to-orthogonal rifting models}

The final results are from Series E, which included models with an initial $30^{\circ}$ oblique rifting, followed by an orthogonal rifting phase $\left(\alpha=0^{\circ}\right)$ (Figure 6), with the divergence rate being kept constant at $20 \mathrm{~mm} / \mathrm{h}$.

\subsection{1 | Model axis-parallel VD Models E1-E3}

Initial oblique rifting had a clear effect on Model E1 with a model axis-parallel VD but without seeds, when compared to its reference equivalent, Model A1 (Figures 2a and 6a). In Model E1, two deformation zones developed along the VD during the earliest stages, with en echelon grabens forming towards the end of the first phase (instead of the model axis-parallel faulting in Model A1, Figures $2 \mathrm{a}$ and $6 \mathrm{a}_{\mathrm{I}-\mathrm{III}}$ ). After a shift to orthogonal rifting, the en echelon grabens in Model E1 continued to be active, but new faults and grabens showed a tendency to grow sub-perpendicular to the new divergence direction, so that the final structures were somewhat curved at the tips (Figure $6 \mathrm{a}_{\mathrm{IV}-\mathrm{VI}}$ ).

By contrast, when seeds were present in Models E2 and E3 (Figure 6b,c), they strongly controlled where deformation was localised, resulting in structures that were very similar to the reference Models A2 and A3 (Figure $2 \mathrm{~b}, \mathrm{c})$. There is, however, some variation in Model E3, in the form of more grabens being situated between the seedinduced structures, which form sub-perpendicular to the divergence direction (Figure 6c). 


\section{Series D - Orthogonal-to-oblique rifting models}

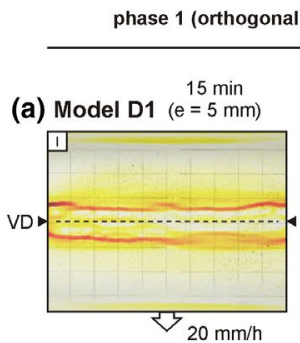

(b) Model D2
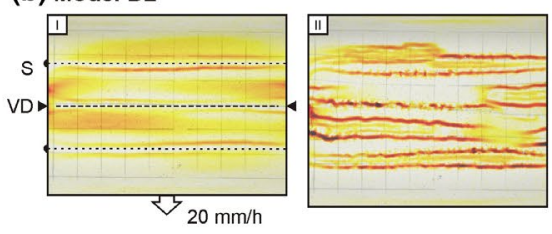

(c) Model D3
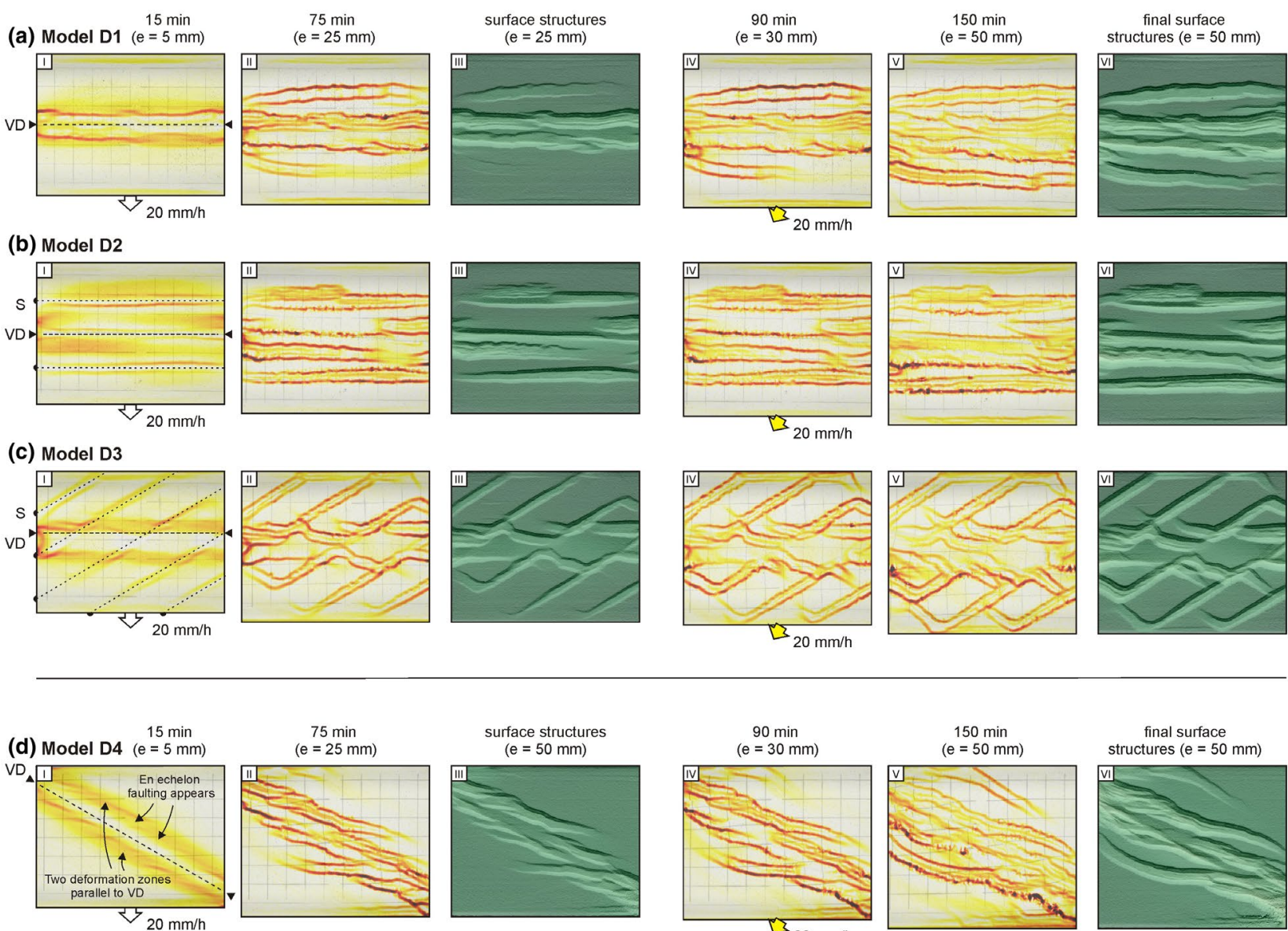

(e) Model D5
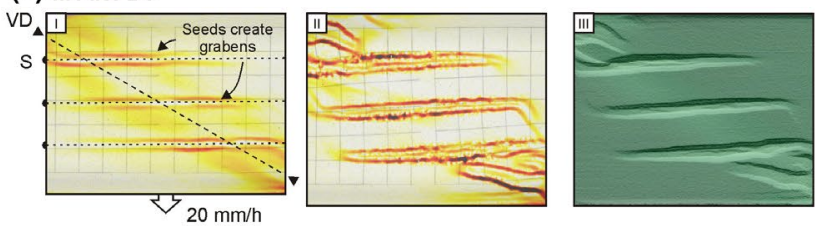

(f) Model D6
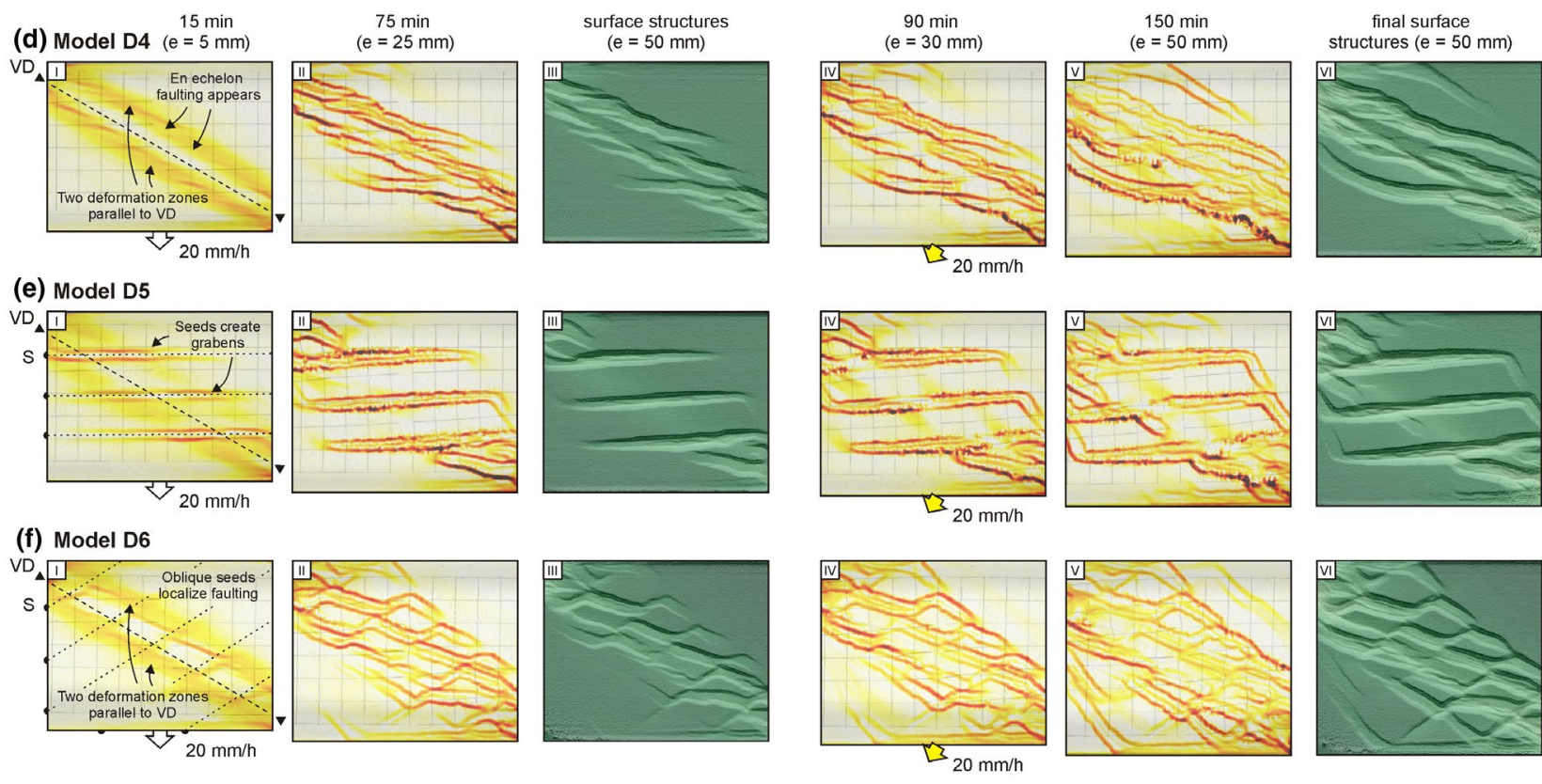
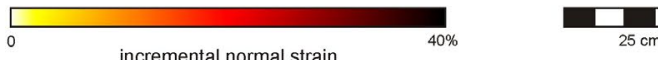

$25 \mathrm{~cm}$
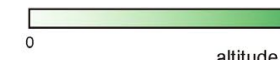

altitude

F I G U RE 5 Model PIV and topography analysis result from Series D involving a first phase of orthogonal rifting $\left(\alpha=0^{\circ}\right)$ followed by a second phase of oblique rifting $\left(\alpha=30^{\circ}\right)$. The divergence rate was constant $(20 \mathrm{~mm} / \mathrm{h})$ during both phases. Divergence increments for PIV analysis were $5 \mathrm{~mm}$. S, seeds; VD, velocity discontinuity

\subsection{2 | Oblique VD Models E4-E6}

Oblique rifting Model E4 with a $30^{\circ}$ oblique VD had an initial divergence direction perpendicular to the VD (Figure $\left.6 \mathrm{~d}_{\mathrm{I}-\mathrm{III}}\right)$. As a result, the VD-parallel strain zones developed two grabens on both sides of the VD (Figure $6 \mathrm{~d}_{\text {I-III }}$ ), rather than the en echelon graben arrangement in reference Model A4 (Figure $2 \mathrm{~d}_{\text {I-III }}$ ). The first phase in Model 


\section{Series E - Oblique-to-orthogonal rifting models}
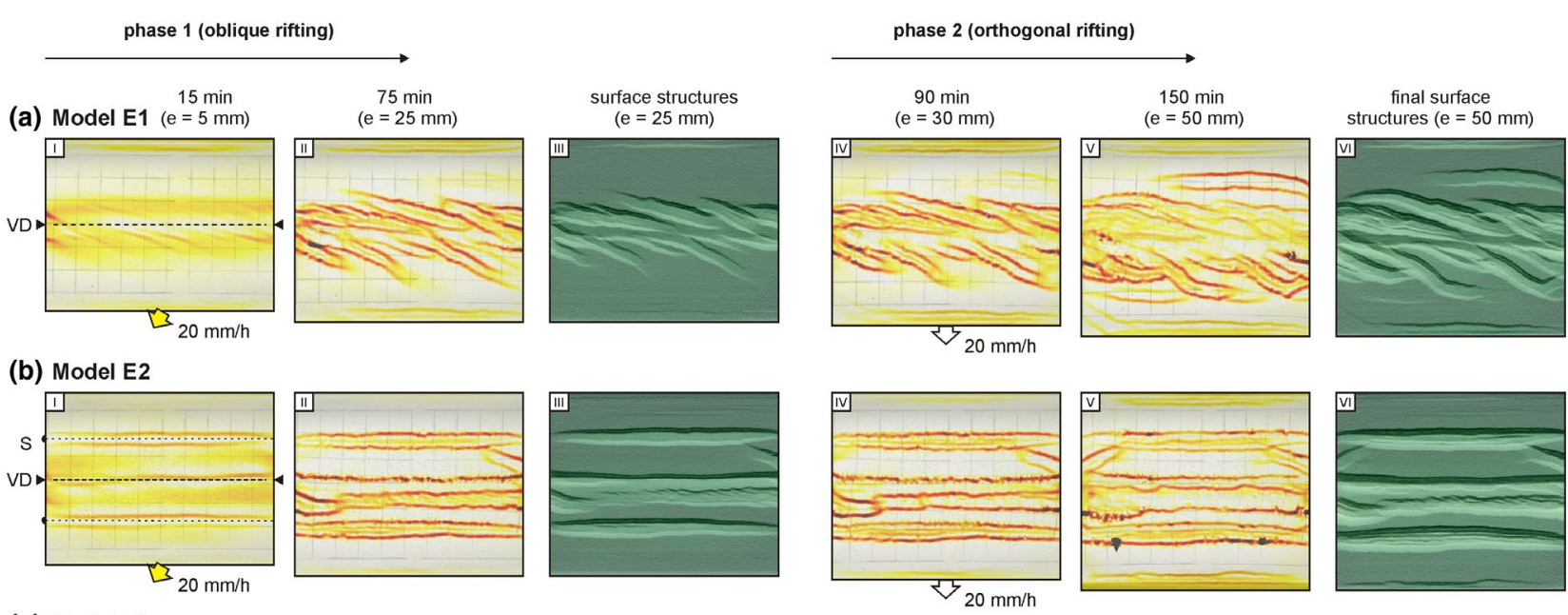

(b) Model E2
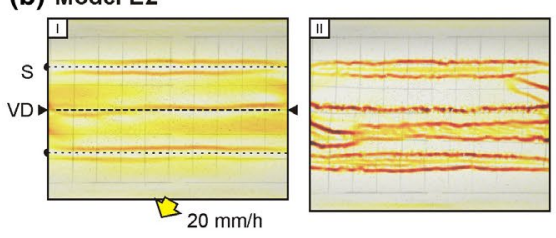

(c) Model E3
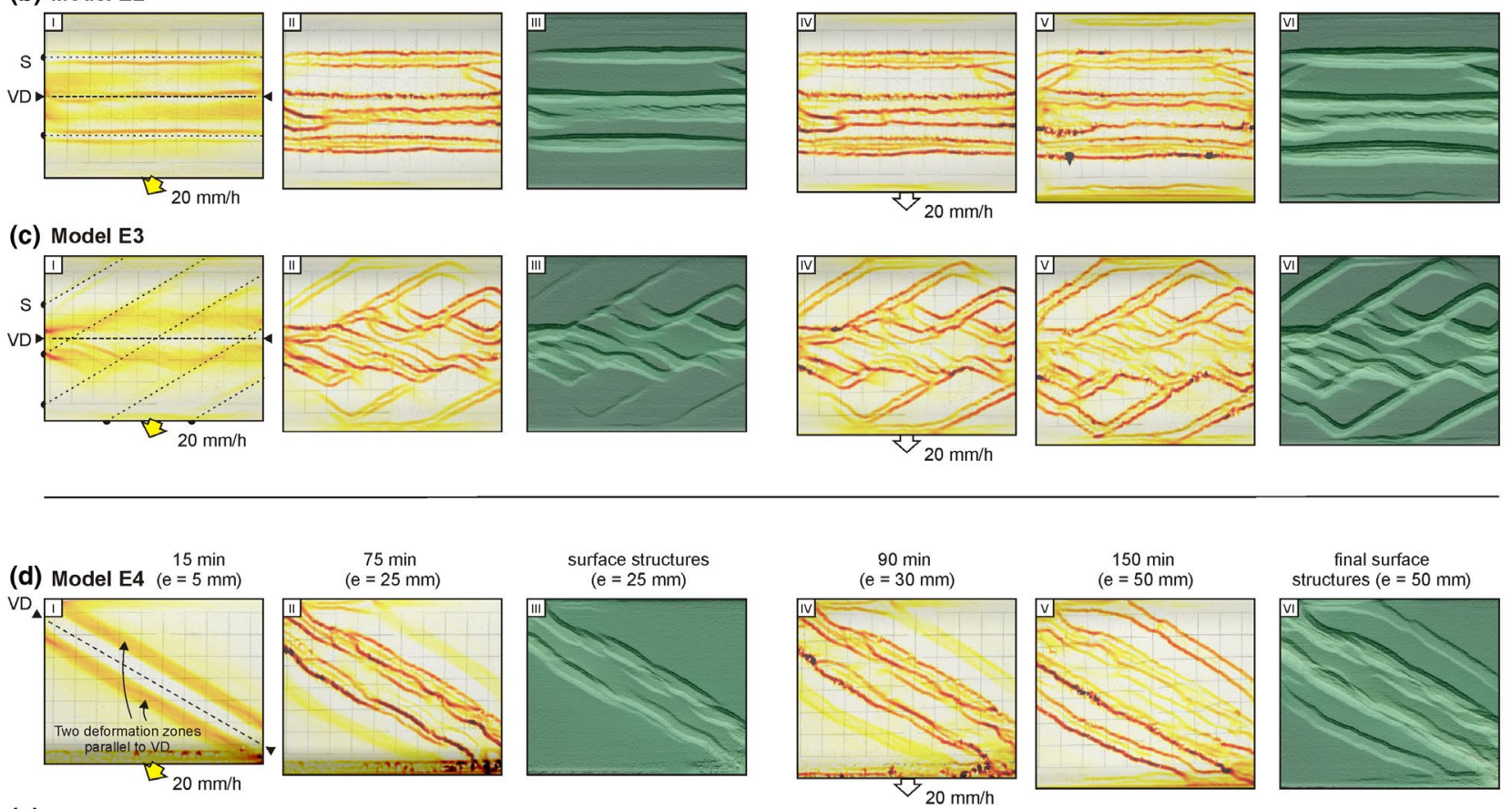

(e) Model E5
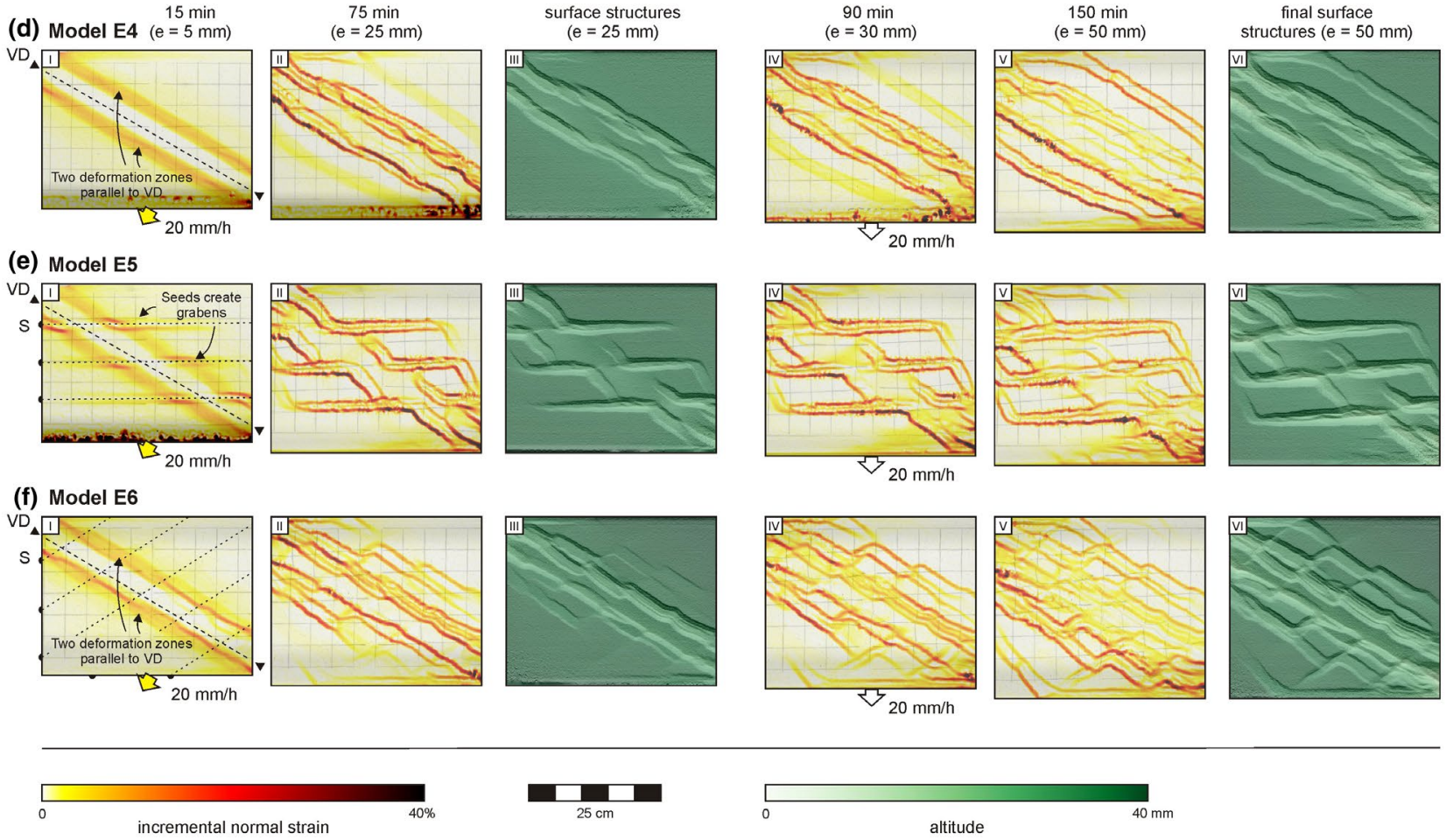

F I G U R E 6 Model PIV and topography analysis result from Series E involving a first phase of oblique rifting $\left(\alpha=30^{\circ}\right)$ followed by a second phase of orthogonal rifting $\left(\alpha=0^{\circ}\right)$. The divergence rate was constant $(20 \mathrm{~mm} / \mathrm{h})$ during both phases. Divergence increments for PIV analysis were $5 \mathrm{~mm}$. S, seeds; VD, velocity discontinuity

E4 also generated some faint strain zones farther away from the central VD-aligned grabens (Figure $6 \mathrm{~d}_{\mathrm{II}}$ ). These latter strain zones subsequently developed into secondary grabens during the second (orthogonal) rifting phase, without clear indications of a change of deformation style (Figure $6 \mathrm{~d}_{\mathrm{IV}-\mathrm{VI}}$ ). 
In Models E5 and E6, seed activation was affected by initial oblique rifting (Figure $\left.6 \mathrm{e}_{\mathrm{I}-\mathrm{III}}, \mathrm{f}_{\mathrm{I}-\mathrm{III}}\right)$. In comparison to reference Models A5 and A6 (Figure $2 \mathrm{e}_{\mathrm{I}-\mathrm{III}}, \mathrm{f}_{\mathrm{I}-\mathrm{III}}$ ), the seeds in these last Series 5 models were poorly reactivated, whereas the VD-induced grabens were significantly better developed. During the second phase of orthogonal rifting, the seed-induced structures became dominant in Model E5, and deformation became rather distributed in Model E6. Overall, the final structures in Models E5 and E6 were very similar to those in reference Models A5 and A6 (Figures $2 \mathrm{e}_{\mathrm{VI}}, \mathrm{f}_{\mathrm{VI}}$ and $6 \mathrm{e}_{\mathrm{VI}}, \mathrm{f}_{\mathrm{VI}}$ ).

\section{4 | DISCUSSION}

\section{1 $\quad$ Synopsis of model results and comparison with previous model results}

We present an overview of our model results in Figures 7 and 8 , which form the basis for the synopsis outlined in the following sections. Figure 7 contains a compilation of PIV results (maximum normal strain data) whereas Figure 8 summarises topography analysis results. These overview figures include data from all reference models, but for the multiphase rifting models, we focus on the results from experiments with a model-axis parallel VD $\left(\theta_{\mathrm{VD}}=0^{\circ}\right)$. The reaction of these models to the changing kinematic conditions were quite representative for the oblique VD models as well, but note that a full overview of all model results presented in this paper (regarding both strain and topography) is provided in the Appendix (Figures A1 and A2). We subsequently compare these results to previously published analogue and numerical modelling results.

\subsection{1 | Reference models}

The results of the reference models from model Series A provide clear insights into the influence of VD and seed geometry on rift structures (Figures $7 \mathrm{a}-\mathrm{f}$ and $8 \mathrm{a}-\mathrm{f}$ ). We found that without seeds, a model axis-parallel VD $\left(\theta_{\mathrm{VD}}=0^{\circ}\right)$ tends to form a central (double) rift structure with laterally through-going faults, in contrast to the en echelon graben structures developing along an oblique VD (Figures 7a,d and 8a,d). These results are clearly related to the divergence direction with respect to the VD (orthogonal vs. oblique). But adding seeds diverted deformation away from the VD-induced grabens (Figures $7 b, c, e, f$ and $8 b, c, e, f)$. Here a clear competition between the VD and seeds occurred, highlighting that the structural trends related to weaknesses oriented orthogonally to the divergence direction dominated the model surface expression in our experiments (e.g. compare Model A2 to Model A5 in Figures 7b,e and 8b,e). The seeds furthermore induce segmentation of the VDrelated rift zone and create a rift arrangement with different structural orientations.

Our reference model results are consistent with the observations from previous modelling studies. These earlier studies showed that, without a seed, a double graben forms due to the presence of shallow-dipping shear zones originating from the VD or mantle discontinuity (e.g. Dyksterhuis et al., 2007; Michon \& Merle, 2000, 2003; Oliveira et al., in review; Tron \& Brun, 1991; Zwaan et al., 2019, 2021a) (Figures 7a and 8a). The en echelon grabens developing along an oblique VD (Figures $7 \mathrm{~d}$ and 8d) are typical for such model set-ups, as the effective stretching direction is locally deviated by the oblique VD (e.g. Bonini et al., 1997; Brune \& Autin, 2013; Clifton et al., 2000; Duclaux et al., 2020; Morley, 2010; Ruh, 2019; Reiter, 2021; Tron \& Brun, 1991; Van Wijk, 2005; Zwaan et al., 2021a).

Also the varying effects of the simulated crustal weaknesses in our models are in agreement with previous model results. Models by, for example McClay and White (1995), Bellahsen and Daniel (2005), Zwaan and Schreurs (2017), Deng et al. (2018), Molnar et al. (2019), Maestrelli et al. (2020), and references therein showed that inherited weaknesses oriented obliquely to the divergence direction are less favourably oriented for reactivation, and thus less likely to localise deformation. Conversely, weaknesses that are oriented orthogonally to the divergence direction are more likely to localise deformation during rifting. Zwaan et al. (2021a) described how, as a result of this kinematic relationship, simulated crustal and mantle weaknesses may compete during rifting, with one type of weakness dominating the system, often if that weakness is oriented perpendicular to the divergence direction. This same process was clearly observed in our models and led to complex rift structures with different structural orientations forming during a single rift event (Figures $7 \mathrm{~b}, \mathrm{c}, \mathrm{e}, \mathrm{f}$ and $8 \mathrm{~b}, \mathrm{c}, \mathrm{e}, \mathrm{f})$. We would also like to point out that next to their orientation with respect to the divergence direction, also the type of modelled crustal weakness (thick or thin seed, or pre-cut faults) affects their potential for reactivation: more pronounced weaknesses are more likely to reactivate (e.g. Osagiede et al., 2021; Wang et al., 2021; Zwaan et al., 2021a).

\subsubsection{Effects of divergence rate variations}

The models from Series B and C provide clear insights into the effects of changing divergence rates during rifting (Figures $7 \mathrm{~g}-1$ and $8 \mathrm{~g}-\mathrm{l}$ ). With respect to the reference 
General set-up
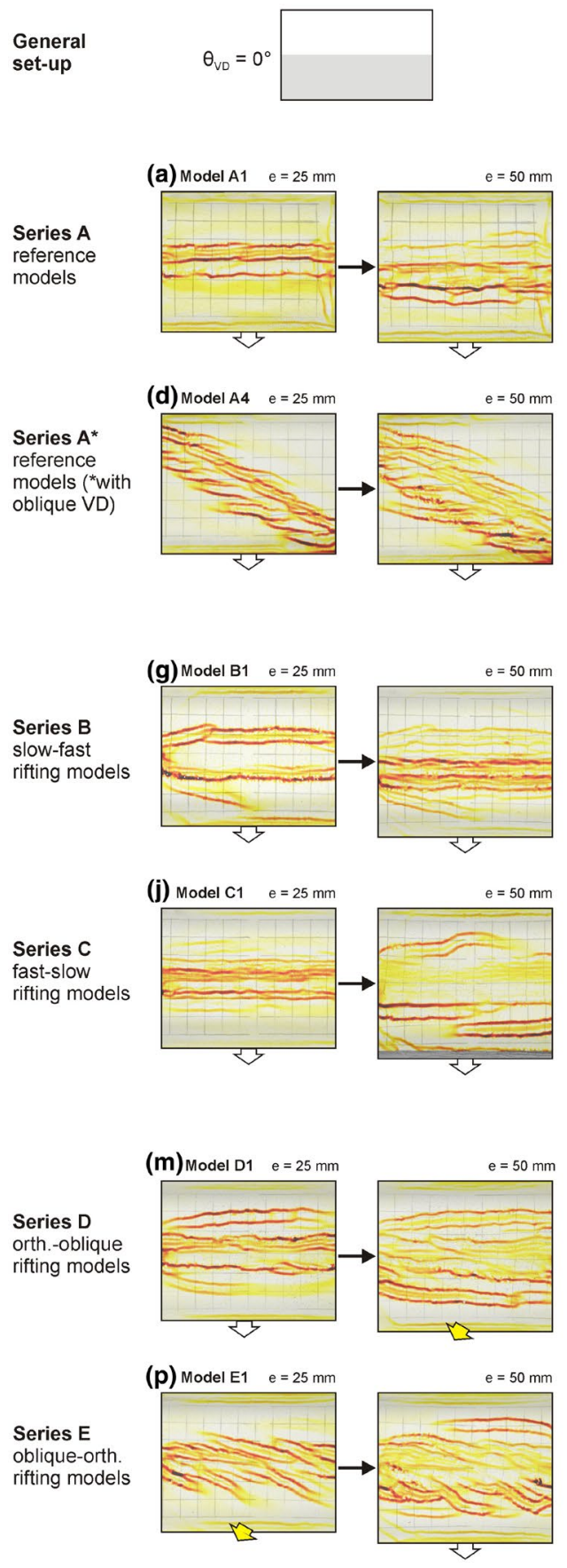
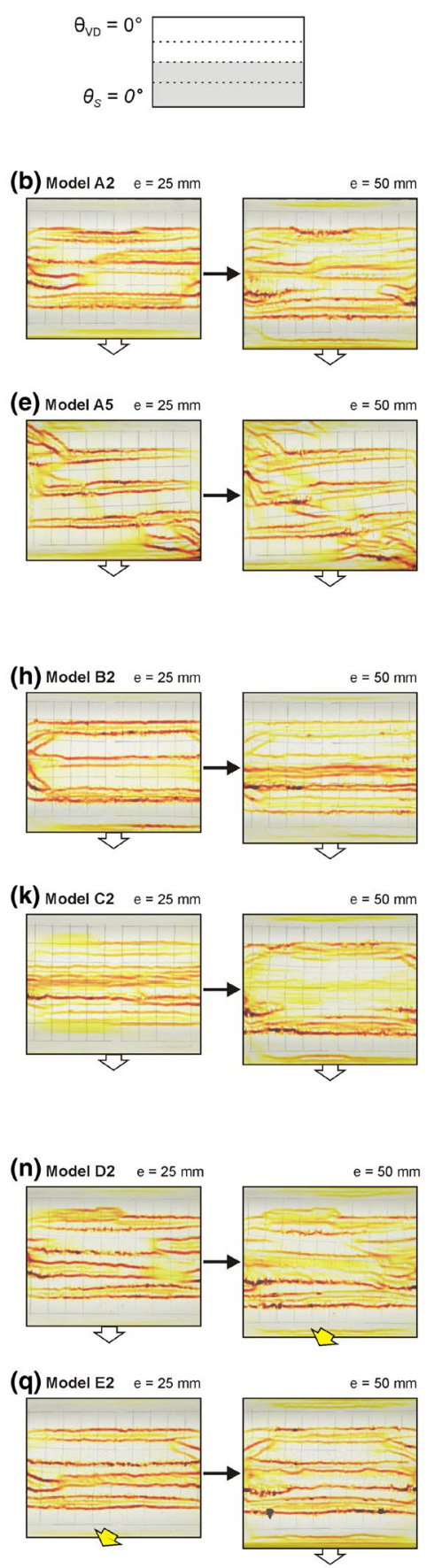
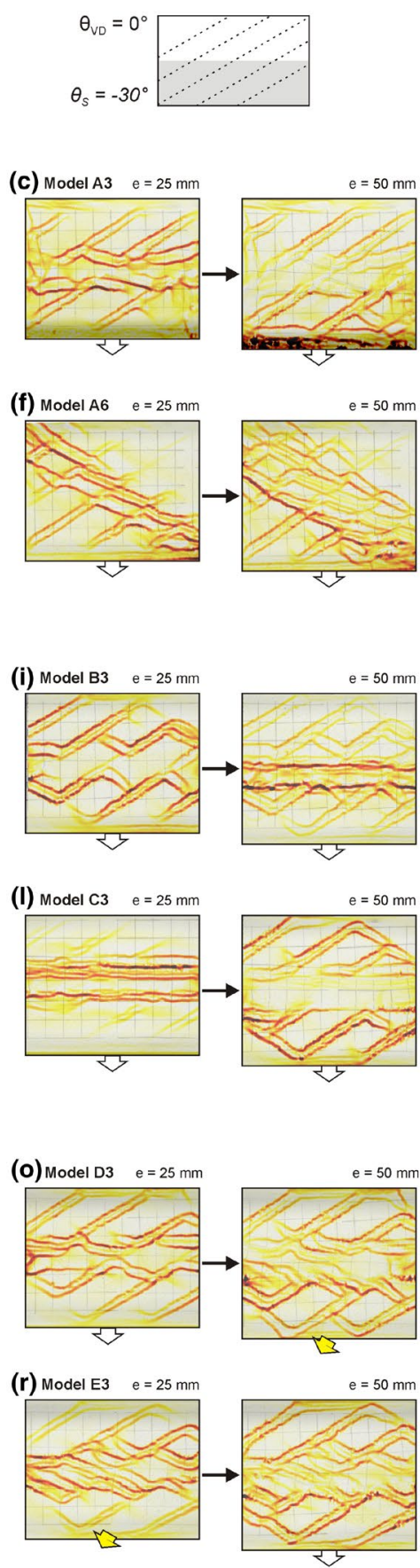

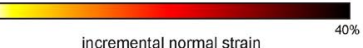

F I G U RE 7 Overview of maximum normal strain evolution of the reference models from Series A, and of multiphase rifting models from Series B-E with a model axis-parallel VD $\left(\theta_{\mathrm{VD}}=0^{\circ}\right)$ that are representative of the influence of changes in divergence rate and direction. Divergence increments for PIV analysis were $5 \mathrm{~mm}$. A complete overview of maximum normal strain results of all models presented in this paper is included in the Appendix (Figure A1)

models with intermediate divergence rates (Figures $7 \mathrm{a}-\mathrm{f}$ and $8 \mathrm{a}-\mathrm{f})$, slow $(10 \mathrm{~mm} / \mathrm{h})$ rifting resulted in (more) distributed deformation, and in models with seeds, slow rifting caused increased localisation of faulting along these seeds compared to models with higher extension rates.
By contrast, models involving fast rifting $(100 \mathrm{~mm} / \mathrm{h})$ revealed very strong localisation of deformation along the VD. This relation between divergence rate and the development of structures along either the VD or seeds is valid for localisation of deformation in both the first and second 
General set-up
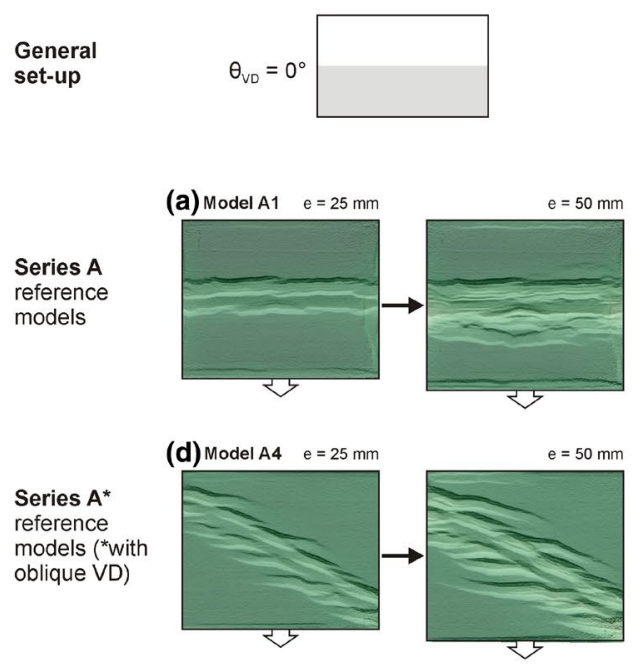

Series $A^{*}$ reference models (*with oblique VD)
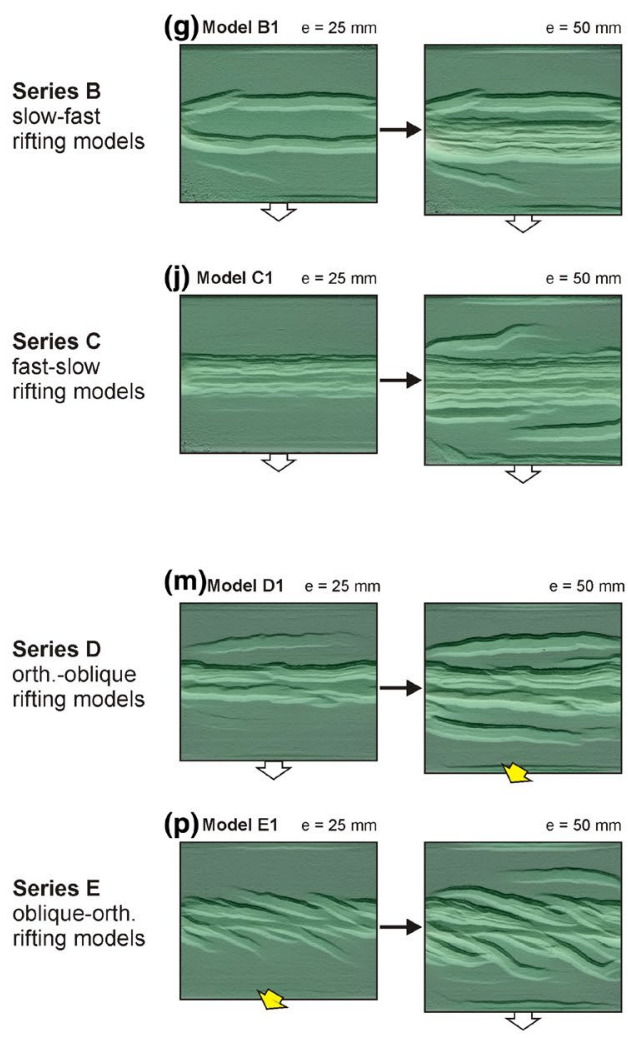
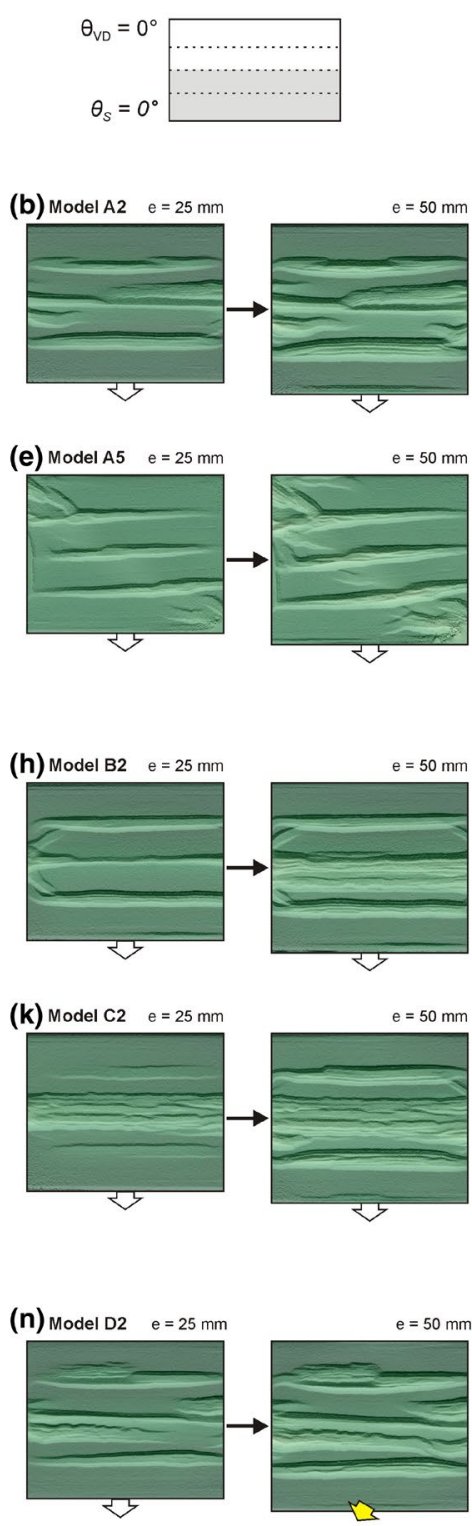

(q) Model E2 e=25 mm
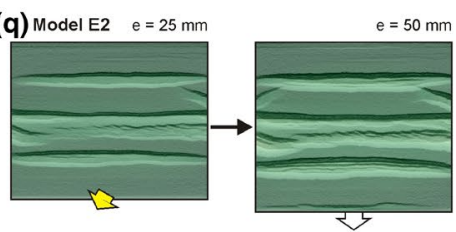
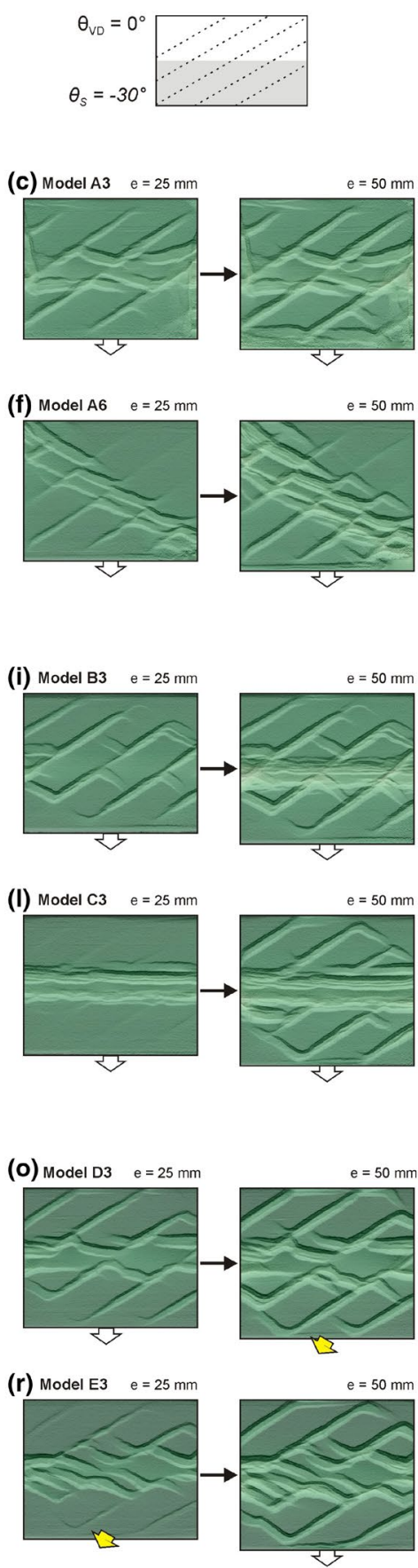

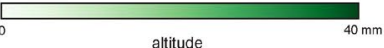

F I G U RE 8 Overview of topographic evolution of the reference models from Series A, and of multiphase rifting models from Series B-E with a model axis-parallel VD $\left(\theta_{\mathrm{VD}}=0^{\circ}\right)$ that are representative of the influence of changes in divergence rate and direction. A complete overview of topography results of all models presented in this paper is included in the Appendix (Figure A2)

phase and is especially well illustrated by the strain maps (Figure $7 \mathrm{~g}-1$ ). Strikingly, the order of the divergence rate variations we applied in our models did not cause significant differences in this relation: the deformation regime during the second phase simply overprinted the structures already established during the first rifting phase (Figures
$7 \mathrm{~g}-1$ and $8 \mathrm{~g}-1)$. As a result, the final structures in the models with changing divergence rates but with the same general set-up were very similar, even if their evolution was very different (e.g. compare Model B3 to Model C3, Figure 8i,l). In fact, the final structures (in terms of fault patterns and structural orientations) in these models with 
changing divergence rates were also very similar to those found in the reference models (Figure 8a-f).

The general effects of divergence rates on rift evolution observed in our models are complex and partially documented in previous modelling publications, but comparing our model results to those from previous publications also highlights an apparent paradox. Firstly, slow rifting in our models localised deformation along the simulated crustal weaknesses (Figures $7 \mathrm{~h}, \mathrm{i}, \mathrm{k}, 1,8 \mathrm{~h}, \mathrm{i}, \mathrm{k}, 1$, and $9 \mathrm{a}$ ), as previously reported by, for example Zwaan et al. (2016). On the other hand, the fast-rifting models strongly focused deformation along the VD instead (as hinted at by Zwaan et al., 2021a), which is, however, in contrast to the distributed deformation or (wide) rifting style due to high divergence rates described by, for example Brun (1999), Nestola et al. (2015) and Zwaan et al. (2016). The key factor in this paradox is the basal model boundary condition (Zwaan et al., 2019). When a strong mantle with a (single) VD is simulated, and coupling between lithospheric layers is sufficiently high due to high divergence rates that cause the lower crustal layer to strengthen (or by having a strong, or thin lower crustal layer in general), this VD will induce localised deformation in the upper crustal layer (Figure 9b). However, if the simulated mantle stretches uniformly (e.g. by using a model set-up with a foam base or a rubber sheet), high coupling leads to dominant distributed deformation in the upper crustal layer (e.g. Schlagenhauf et al., 2008; Zwaan et al., 2019) (Figure 9d), even if seeds are present (Zwaan et al., 2016). A similar, but somewhat less constrained distributed boundary condition is found in models with a viscous mantle floating on a fluid asthenosphere analogue (e.g. Molnar et al., 2017; Samsu et al., 2021). By contrast, low coupling due to slow rifting (or a weak or thick lower crust) is known to isolate the upper crustal layer from the simulated mantle, so that deformation is free to localise along heterogeneities within the upper crustal layer (e.g. Zwaan et al., 2019) (Figure 9a,c). Moderate divergence rates in combination with a distributed deformation basal boundary condition lead to a hybrid deformation style, with both widespread faulting and localisation along the seeds (Zwaan et al., 2016).

Although several works have addressed the general effects of divergence rates during rifting (e.g. Brun, 1999; Zwaan et al., 2016, 2021a), little attention has been dedicated to the effects of changing divergence rates over time. To our knowledge, only Brun and Tron (1993) have applied such multiphase rifting in brittle-viscous models with a VD (but without seeds). Their model results also indicate that initial high coupling due to high divergence rates localises deformation along the VD, whereas subsequent lower divergence rates tend to distribute deformation over a broader zone along the VD, in line with our model results (Figure 9b, b'). Moreover, recent 2D numerical work by Naliboff et al. (2017) shows that externally imposed increasing divergence rates help localise deformation along the rift axis, similar to the enhanced localisation along the VD in our models. Furthermore, Brune et al. (2016) have numerically modelled increasing divergence rates through force-boundary conditions. However, in these numerical models, the increase in divergence rate is the result of necking and weakening of the lithosphere allowing faster plate motion, whereas necking (or localisation along the VD) in our models is the result of faster plate motion itself (Figure 9a,a'). Due to these fundamental differences in boundary conditions between our models and the study of Brune et al. (2016) a comparison is challenging, but the sequence of events is the same nevertheless.

\subsection{3 | Effects of divergence direction variations}

Finally, the results from model Series D and E show how changing divergence directions affected rift structures to only a minor degree (Figures $7 \mathrm{~m}-\mathrm{r}$ and $8 \mathrm{~m}-\mathrm{r}$ ). Despite some slight differences, the models from Series D, which had an initial phase of orthogonal rifting, created very similar first-phase structures to those observed in the early stages of the reference models (Figures $7 \mathrm{a}-\mathrm{c}, \mathrm{m}-\mathrm{o}$ and $8 \mathrm{a}-\mathrm{c}, \mathrm{m}-\mathrm{o})$. The second phase of oblique rifting did not significantly alter the well-established structural arrangement from the first orthogonal rifting phase, so that the final structures in our Series D models were very similar to those from Series A (Figure 8a-c,m-o). By contrast, our Series E models showed clear deviations from the patterns in previous models (Figures $7 \mathrm{p}-\mathrm{r}$ and $8 \mathrm{p}-\mathrm{r}$ ); Model E1 developed a series of en echelon grabens along the VD, similar to those found in reference Model A4 (Figure $8 \mathrm{~d}, \mathrm{e})$. But when seeds were present, they localised significant amounts, if not most, of the deformation; only minor details such as the orientation of VD-induced grabens would betray the occurrence of an initial phase of oblique rifting (Figures $7 \mathrm{q}-\mathrm{r}$ and $8 \mathrm{q}-\mathrm{r}$ ). Similar to the Series D models, a shift in divergence direction, here from oblique to orthogonal, did not significantly affect the subsequent rift evolution (Figures $7 \mathrm{~m}-\mathrm{r}$ and $8 \mathrm{~m}-\mathrm{r}$ ). Only when seeds were absent, a slight realignment of new faults oriented near-orthogonally to the divergence direction occurred (Figures $7 \mathrm{p}$ and $8 \mathrm{p}$ ).

While the impact of changing divergence rates remains poorly explored in the academic literature, more attention has been dedicated to the effects of changing divergence 


\section{Localized deformation basal boundary condition}

(a) Initial slow rifting:

no coupling: localization within UC

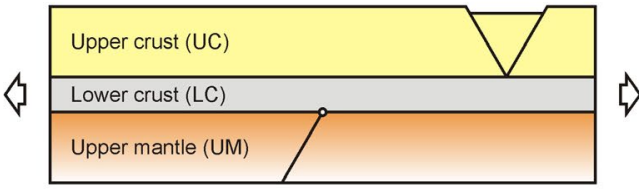

(a') Subsequent fast rifting: coupling and overprinting of previous structures by VD-induced grabens

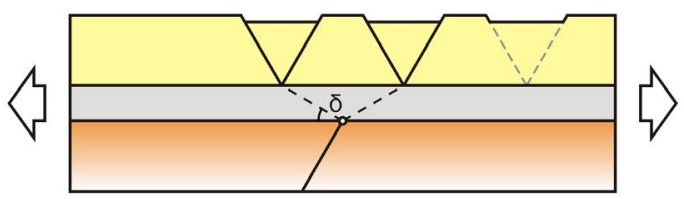

(b) Initial fast rifting:

coupling: localization above VD

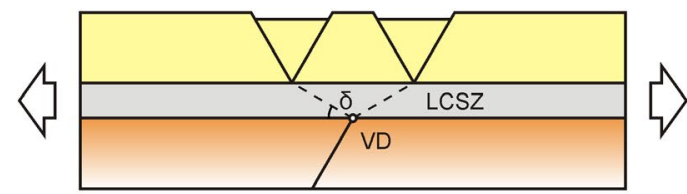

(b') Subsequent slow rifting: decoupling and localization in UC, away from previous structures

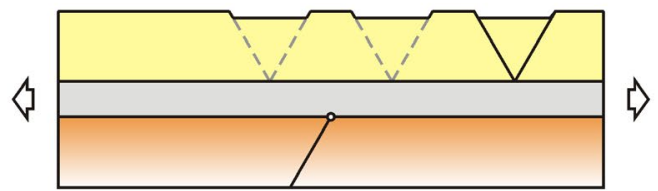

\section{Distributed deformation basal boundary condition}

(c) Slow rifting:

no coupling: localization within UC

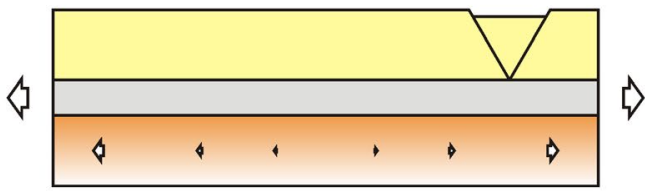

(d) Fast rifting:

coupling: transfer of distributed extension into UC

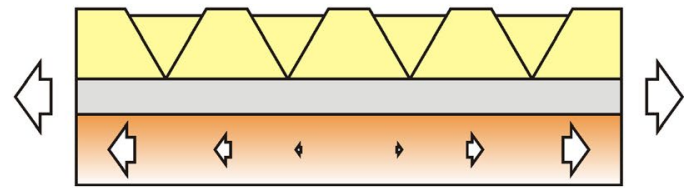

F I G U R E 9 General effects of divergence rates on lower crustal strength and coupling between the upper crust and upper mantle, affecting rift evolution in brittle-viscous models. ( $a, b)$ Effects of changing divergence rates as observed in our models. (a) Slow rifting causes decoupling of the upper crust (UC) from the upper mantle (UM) due to weakening of the lower crust (LC) in between, leading to localisation of faulting within the upper crust (UC), unaffected by any mantle weakness or velocity discontinuity (VD). (a') Subsequent fast rifting strengthens the LC and enhanced coupling between the UC and UM, leading to overprinting of previous structures by localised rift development as deformation is transferred from the VD to the UC through lower crustal shear zones (LCSZ) with dip angle $\delta$. Please note that the location of the graben in (a) is chosen arbitrarily, as it is not affected by the VD. (b) Initial fast rifting strengthens LC and enhances coupling between the UC and UM, leading to localised rift development. (b'). Subsequent slow rifting causes decoupling between UC and $\mathrm{UM}$, leading to localisation of faulting within the upper crust that is independent of the VD and overprints the previous structures. (c, d) Expected effects of different divergence rates in models with a set-up involving a ductile upper mantle layer that distributes stretching. (c) Slow rifting causes weakening of the LC and decoupling of the UC from the UM (NB: the graben location is arbitrarily chosen, similar to [9a]), whereas (d) fast rifting leads to strengthening of the LC and coupling and transfer of distributed deformation into the UC. Modified after Zwaan et al. (2019, 2021a)

directions. The general observation that structures developing during the first rifting phase are likely to control subsequent deformation phases involving a different divergence direction is also reported by Bonini et al. (1997), Bellahsen and Daniel (2005); Dubois et al. (2002); Henza et al. (2010, 2011), Withjack et al. (2017) and Wang et al. (2021). Interestingly, Virgo et al. (2014) made somewhat similar observations in their numerical models of smallscale fracture network development in changing stress fields. Yet, as pointed out by Henza et al. (2010, 2011) and Wang et al. (2021), the amount of deformation during the first rifting phase is a dominant factor. If only minor deformation occurred during this first phase, the resulting structures may not have sufficiently developed to localise subsequent deformation. A hint of this effect is visible in Model E1, where the new faults away from the central rift during the second phase did realign to be striking near-orthogonal to the divergence direction (Figures $7 p$ 
and $8 \mathrm{p}$ ). This argument can also be made for pre-existing structures in general, whether resulting from an initial rifting phase or any other preceding tectonic phase (e.g. Zwaan et al., 2021a). Furthermore, as discussed in Section 4.1.1, also the direction of such structures with respect to the divergence direction is expected to have an important influence on whether these inherited structures will reactivate or not.

\section{2 | Relations between factors affecting rifting}

Although our model results show that divergence rate, affecting the strength of the lower crust and thus the degree of coupling between the upper crust and upper mantle, is a key parameter affecting early rift evolution, we must consider a wider variety of parameters to get a better grasp of what factors control the evolution of continental rift systems. By combining observations from our models and from previous brittle-viscous modelling studies, we drafted a more general overview of these factors and their relative importance, that can serve as a 'recipe' for assessing rift evolution (Figure 10):

- As pointed out in a similar graph in the review paper by Corti et al. (2003), as well as in Zwaan et al. (2019) and Zwaan and Schreurs (2021), the structure of the lithosphere, that is the presence and thickness of the ductile lower crust, is a key factor during rifting (Figure $10 \mathrm{a}-\mathrm{c})$. In the absence of such a layer, deformation is fully controlled by the mantle (Figure 10c,f,g). Such mantle-controlled deformation in the crust can be either localised or distributed (e.g. Bellahsen et al., 2003; Wijns et al., 2005; Zwaan et al., 2019). By contrast, a very thick weak lower crustal layer fully decouples the crust from the underlying mantle, so that the upper crust is free to deform independently from the mantle (Figure 10a,d,e).

- The divergence rate become an important factor when the weak lower crustal layer is of moderate thickness since its rheology is strain-rate dependent (Figure 10b). As such, fast rifting tends to strengthen the lower crustal layer, leading to increased coupling between the upper mantle and upper crust so that the mantle will have more control on deformation in the upper crust (Figure 101,m). By contrast, when rifting is slow, the lower crustal layer will remain weaker, leading to decoupling and less influence of the underlying mantle (Figure 10h,i,n,q,r).

- When strong coupling between the upper mantle and upper crust occurs due to fast rifting in a system with a moderately thick lower crustal layer, the deformation in the upper mantle determines what type of deformation is induced in the upper crust (Figure 10l,m). In case of a stable continental lithosphere, we expect a strong upper mantle layer (e.g. Brun, 1999), and a fracture or shear zone in this strong upper mantle would subsequently strongly localise deformation in the overlying crust (e.g. Oliveira et al., in review, Figures $9 \mathrm{~b}$ and 101). The orientation of the mantle weakness with respect to the divergence direction then determines what kind of faulting will form within the localised rift zone in the upper crustal layer, and will overrule the influence of any crustal weakness (Figure 10o,p). Yet, when the upper mantle behaves in a more ductile fashion, involving more distributed deformation, we would expect this distributed deformation to be transferred onto the upper crust (e.g. Zwaan et al., 2016, Figure 10m), and the faulting in the upper crustal layer to be generally oriented (sub-) perpendicular to the divergence direction. Note that these general effects would also occur in a highly coupled system without a weak lower crustal layer at all (Figure 10f,g).

- However, if coupling between the upper mantle and upper crust (in a system with a moderately thick lower crust thickness) remains low due to slow rifting, we may expect that deformation in the upper crust will be dominated by pre-existing weaknesses from previous tectonic phases (including a potential initial rifting phase), if such weaknesses are present (Figure 10h,i). How well these weaknesses will localise deformation depends on the degree they weaken the upper crust, and how they are oriented with respect to the divergence direction (orthogonal weaknesses react best, oblique weaknesses much less so) (Bellahsen \& Daniel, 2005; Henza et al., 2010, 2011; Wang et al., 2021; Zwaan et al., 2021) (Figure 10n,q,r). If different orientations of crustal weaknesses are present, subsequent rift arrangements are expected to be complex (e.g. Maestrelli et al., 2020). Note that these same effects should also occur in a system with a very thick lower crustal layer causing decoupling between the upper crustal and mantle layers (Figure 10d,e).

- In the case of moderate coupling between the upper mantle and upper crust, we expect that both the mantle (either deforming in a localised or distributed fashion) and weaknesses in the crust will affect subsequent rifting (Figure 10j,k). These rift structures have been shown to be the most intricate as the controlling factors in both lithospheric layers will interact and compete (Molnar et al., 2020; Zwaan et al., 2021, this study) (Figure 10u,v). Similar to the low-coupling case, the orientation of mantle- and crustal weaknesses to the divergence direction is of great importance, defining which factor will best localise deformation. But distributed deformation in 


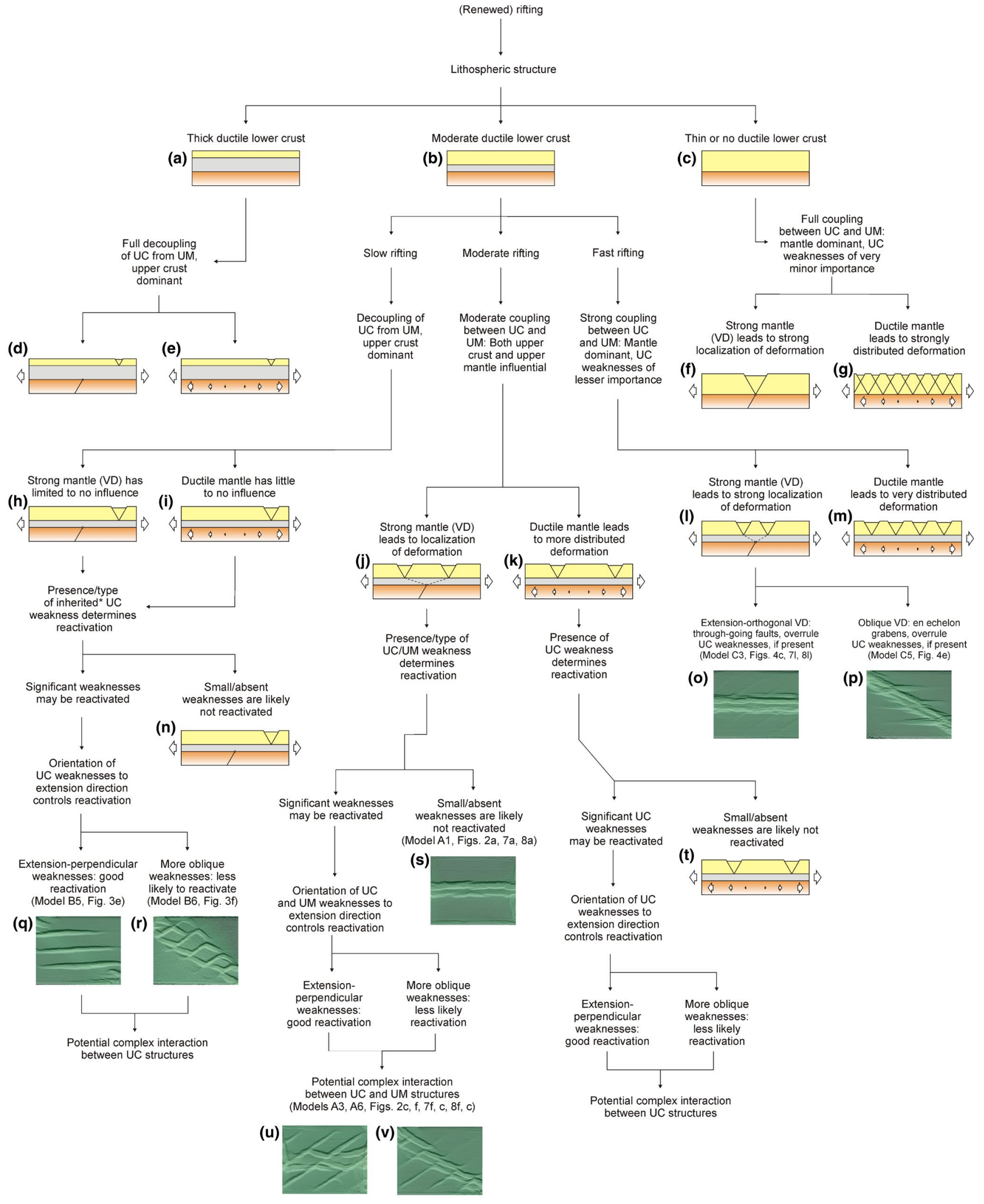

F I G U R E 10 Flow diagram with the relations between the various factors affecting continental rift evolution, based on brittle-viscous models from this study and previous models. Sections illustrate 2D effects and are oriented in the direction of divergence, whereas maps show more complex 3D effects, where appropriate. For legend see Figures 8 and 9. Note that, although the flow chart does not elaborate on the thick and absent weak lower crust scenarios (i.e. full decoupling and full coupling, respectively), we should expect very similar influences of the mantle and crustal weaknesses to those described for the moderate lower crust settings with slow and fast extension (i.e. decoupling and strong coupling), respectively. See text (Section 4.2) for details. VD, velocity discontinuity; UC, upper crust; UM, upper mantle 
the mantle may lead to a degree of regional background overprinting by distributed deformation (Zwaan et al., 2016).

Note that Figure 10 classifies the different types of deformation related to the various factors during a single rift phase. When assessing rift systems involving multiple rift phases with different divergence velocities or directions, the diagram can be used in a serial fashion, each time starting from the top.

\section{3 | Model strengths and limitations}

Although our models provide valuable insights into the effects of inherited weaknesses and multiphase rifting on rift systems, our models have some limitations that need to be taken into account when extrapolating their results. Firstly, our simple model set-up did not allow us to model beyond the initial stages of continental rifting and the subsequent necking phase: none of the more advanced processes related to eventual continental break-up and oceanic spreading could be simulated. Indeed, even though we do assume a specific mantle boundary condition with a VD (Zwaan et al., 2019), no thermal effects, magmatic activity or isostatic compensation induced by the rising sub-lithospheric mantle were included in our models. This is, however, an acceptable limitation since these factors are not considered to be of great importance during the early evolution of magmapoor rift systems (stretching to the onset of necking) we aimed to simulate (Chenin, Manatschal, et al., 2019; Chenin et al., 2020). Magma-rich rifts may have a very different evolution since magmatism can strongly localise deformation early on during rifting (e.g. Buck, 2004, 2006; Ebinger, 2005; Zwaan et al., 2020a). The lack of syn-rift sedimentation, that can also have a significant impact on rift evolution by loading and thermal blanketing (e.g. Bialas \& Buck, 2009; Buiter et al., 2008; Burov \& Cloetingh, 1997; Martín-Barajas et al., 2013) was not a major issue due to the limited amounts of accommodation space being generated in these early stages of rifting (Zwaan et al., 2018a). In fact, the relative simplicity of our model set-up is an advantage, as it allowed us to clearly identify the effects of specific parameters on rift evolution (Figures 7 and 8). A final 'limitation' is the fact that large parts of the vast parameter space in terms of divergence directions, rates and styles (e.g. symmetric vs. asymmetric, Allemand \& Brun, 1991), as well as a structural inheritance (different types, orientations, combinations and arrangements) and many other factors ranging from differences in general lithospheric rheology to surface processes, remain unexplored in this work. This could hardly have been otherwise for practical reasons, but the possibilities provide a strong incentive for future modelling efforts (Zwaan \& Schreurs, 2021). Within the context of this study, an especially interesting point of attention could be the application of force- rather than divergence rate (i.e. velocity) boundary conditions that are so important according to Brune et al. (2016).

\subsection{Implications for interpreting natural rift systems}

Our model results have a number of implications for the interpretation of natural rift systems developing in a stable, thermally equilibrated continental lithosphere with a strong upper crustal and upper mantle layer. Firstly, the complex structures formed as a result of the interaction and competition between mantle and crustal weaknesses in our reference models from Series A (Figures $7 \mathrm{a}-\mathrm{f}$ and $8 \mathrm{a}-\mathrm{f}$ ) highlight the suggestion by Reeve et al. (2015) and Zwaan et al. (2021a) that complex rift structures with multiple structural orientations can be formed during a single phase of rifting. As such, when encountering such rift arrangements in the field, as for instance in the North Sea (Erratt et al., 1999, 2010 and references therein), there is no direct need to invoke changes in the divergence direction over time, and divergence was also not necessarily (sub-)orthogonal to either of the normal faults.

However, when changes in divergence rate occur, it can have significant impacts on rift evolution. A shift from slow to fast rifting in our Series B models, as is characteristic for lithospheric necking (Brune et al., 2016) is expected to be associated with a strong localisation of deformation (Figures $7 \mathrm{~g}-\mathrm{i}$ and $8 \mathrm{~g}-\mathrm{i}$ ). In this case, the mantle becomes the dominant factor and any previous structures controlled by crustal weaknesses may diminish or cease to be active (Chenin \& Beaumont, 2013; Chenin, Manatschal, et al., 2019; Figure 9a,a'). Such an increase in divergence rate could perhaps explain the overprinting of the initial Late Jurassic rift structures by differently oriented grabens towards the very end of the Late Jurassic in the North Sea (Erratt et al., 1999). Whether the acceleration of rifting is due to the necking itself while external forces remain constant as suggested by Brune et al. (2016), or whether it can be a result of increasing external forces such as subduction-induced drag on the plates remains an open question. Importantly, a strongly localised but waning rift system as in our Series $\mathrm{C}$ models (Figures $7 \mathrm{j}-1$ and $8 \mathrm{j}-1$ ), might shift to a more distributed deformation style, where upper crustal weaknesses may reactivate as the upper crust becomes decoupled from the mantle (Figure $9 \mathrm{~b}, \mathrm{~b}^{\prime}$ ). The final rift patterns 
as shown in these models can be very complex and can strongly overprint each other, so that the final structures may be very similar, even though the deformation history was quite different.

The results from our models with changing divergence directions suggest that structures formed during an initial phase of rifting will strongly control the localisation of deformation during a subsequent rift phase that involves a different divergence direction. A good example of such changing divergence directions reactivating rift structures from a previous phase is the Afar Rift in East Africa (Chorowicz et al., 1999; Zwaan et al., 2020b, Zwaan, Corti, et al., 2020). Yet, as observed in other modelling studies, as well as in the Turkana Depression in East Africa, a previous minor rifting phase may not build structures impactful enough to significantly control where subsequent deformation localises (e.g. Henza et al., 2010, 2011; Wang et al., 2021). Therefore, when changes in divergence direction are suspected in a natural rift system, careful examination is needed to determine whether the different structural directions did indeed develop during subsequent rift phases, instead of being the result of a complex structural inheritance.

Indeed, careful examination by combining information from different sources is the key to better assessing the evolution of natural rift systems. Structural field studies provide important insights (e.g. Chorowicz et al., 1999; Samsu et al., 2019; Zwaan, Corti, et al., 2020), but particular attention should be dedicated to detailed fault activity analysis through seismic interpretation (e.g. Bell et al., 2014; Claringbould et al., 2017, 2020; Erratt et al., 1999; Phillips et al., 2019). Such fault analyses address the distribution of rift depocenters, their syn-rift sedimentary infill and their relation to faulting, which provides key insights into rift development (e.g. Chao et al., 2021). But an important caveat, as pointed out by Erratt et al. (1999) and Chenin et al. (2015), is that rift basins may experience very limited syn-rift deposition when the system is approaching the necking stage, leading to a 'necking unconformity' (e.g. the Base Cretaceous Unconformity in the North Sea, Chenin et al., 2015), as post-rift deposits start filling in these previously sediment-starved basins. As a result, syn-rift deposits may only provide a limited record of rift development and the post-rift deposits can capture important changes in rift structure and depocenter distribution that are not recorded by (late) syn-rift units. Thus, only by incorporating information from the analysis of both syn-rift and post-rift infill, a more complete overview of rift evolution can be established. Such overviews could subsequently be compared to our model results and our flow diagram, in order to identify what factors might have been at play during rifting (Figures 7, 8, 10, A1, A2).

\section{CONCLUSION}

In this paper, we present an analogue modelling study involving brittle-viscous set-ups to study how multiphase rifting (changes in divergence rate or-direction) in a continental lithosphere containing pre-existing weaknesses in the competent mantle and crust may affect the evolution of a rift system. By examining our model results we come to the following conclusions:

- Complex rift structures can be the result of reactivation of weaknesses in both the mantle and crust during a single phase of rifting involving moderate divergence rates (i.e. moderate lower crustal strength leading to moderate coupling between the mantle and upper crustal layers), without the need to invoke changes in divergence direction over time. The relative importance of these weaknesses is then a function of their impact on the strength of the layer they are situated in, as well as their orientation with respect to the divergence direction.

- Changing the divergence rate and associated changes in lower crustal strength and thus mantle-crustal coupling strongly affects the localisation of deformation. Slow rifting in lithospheres where crust-mantle coupling is weak favours surficial expression of shallow (crustal) weaknesses with respect to weaknesses located in the mantle. Conversely, fast rifting causes strong coupling and a dominance of mantle weaknesses leading to significant localisation of deformation. A shift from slow to fast rifting causes strong localisation along the mantle VD and overprinting of any previous structures controlled by the crustal weaknesses. Conversely, a shift from fast to slow rifting leads to delocalisation and a reactivation of crustal weakness-induced structures. However, the final structures obtained through either shift can be very similar.

- In rift systems that undergo changes in divergence directions, the structures from the first rifting phase may strongly control where subsequent deformation takes place. However, when these first phase structures are only poorly developed, they will likely not have a significant effect on subsequent rifting. During this new rifting phase, these pre-existing structures from the previous deformation phase may simply be ignored, so that a wholly new structural orientation can be established. Therefore, the final result can vary greatly, depending on the magnitude and direction of divergence during the initial rifting phase.

- Placed in a larger framework of brittle-viscous modelling results from previous studies, we obtain useful insights into the relative importance of the various internal and external factors affecting rift evolution 
(Figure 10). It follows that the general structure of the lithosphere (i.e. its layering and the presence of a weak lower curst) is a dominant parameter, followed by divergence rate, the type of deformation in the lithospheric mantle and finally structural inheritance in the upper crust. Within this hierarchy, the interaction between these various factors can lead to a large variety of deformation styles.

- Altogether, our model results highlight that rift evolution may be strongly affected by structural inheritance in both the crust and the mantle and by changes in divergence rate (and to a lesser degree by changes in divergence direction and the amount of divergence). The interplay between these factors may often but not always, lead to very similar end products. Therefore, a detailed investigation of fault activity and to an equal degree basin depocenter distribution over time (including the distribution of both syn- and post-rift strata) is needed to properly determine the structural history of complex rift systems. These insights, summarised in our overview figures and flow chart (Figures 7, 8, 10, A1, A2) provide a strong incentive to revisit the current interpretation of various natural examples.

\section{ACKNOWLEDGEMENTS}

We thank Timothy Schmid, Michael Rudolf, Matthias Rosenau, and the software engineers from LaVision (Dave Hollis, Horst Nagel, Torsten Siebert) for technical support during the PIV analysis in DaVis. We would also like to thank Kirsten Elger for helping us creating the GFZ data publication with the supplementary material (Zwaan et al. 2021b). We thank editor Atle Rotevatn for handling this manuscript, and Michele Cooke, Anidita Samsu and an anonymous reviewer for their detailed feedback that helped us to improve the quality of this publication. The research on which this publication is based was funded by the Swiss National Science Foundation (grant 200021-178731, http://p3.snf. ch/Project-178731), and Open Access publication costs were covered by the University of Bern.

\section{CONFLICT OF INTEREST}

The authors declare that they have no conflict of interest.

\section{PEER REVIEW}

The peer review history for this article is available at https://publons.com/publon/10.1111/bre.12642.

\section{DATA AVAILABILITY STATEMENT}

Images and videos of the models, including PIV analyses results, are freely available in the form of a data publication stored on the GFZ Data Services database (Zwaan et al., 2021b), which can be accessed here: https://doi. org/10.5880/fidgeo.2021.042.

\section{ORCID}

Frank Zwaan (1) https://orcid.org/0000-0001-8226-2132

Pauline Chenin (10) https://orcid.org/0000-0002-2151-5148

Gianreto Manatschal (1) https://orcid.

org/0000-0003-3834-2033

Guido Schreurs (1D https://orcid.org/0000-0002-4544-7514

\section{REFERENCES}

Adam, J., Urai, J. L., Wieneke, B., Oncken, O., Pfeiffer, K., Kukowski, N., Lohrmann, J., Hoth, S., Van der Zee, W., \& Schmatz, J. (2005). Shear localisation and strain distribution during tectonic faulting-New insights from granular-flow experiments and high-resolution optical image correlation techniques. Journal of Structural Geology, 27, 283-301. https://doi. org/10.1016/j.jsg.2004.08.008

Agostini, A., Corti, G., Zeoli, A., \& Mulugeta, G. (2009). Evolution, pattern, and partitioning of deformation during oblique continental rifting: Inferences from lithospheric-scale centrifuge models. Geochemistry, Geophysics, Geosystems, 10, Q11015. https://doi.org/10.1029/2009GC002676

Allemand, P., \& Brun, J.-P. (1991). Width of continental rifts and rheological layering of the lithosphere. Tectonophysics, 27, 283301. https://doi.org/10.1016/0040-1951(91)90314-I

Autin, J., Bellahsen, N., Husson, L., Beslier, M.-O., Leroy, S., \& d'Acremont, E. (2010). Analog models of oblique rifting in a cold lithosphere. Tectonics, 29, TC6016. https://doi.org/10.1029/2010T C002671

Autin, J., Bellahsen, N., Leroy, S., Husson, L., Beslier, M.-O., \& d'Acremont, E. (2013). The role of structural inheritance in oblique rifting: Insights from analogue models and application to the Gulf of Aden. Tectonophysics, 607, 51-64. https://doi. org/10.1016/j.tecto.2013.05.041

Bell, R. E., Jackson, C.- A.-L., Whipp, P. S., \& Clements, B. (2014). Strain migration during multiphase extension: Observations from the northern North Sea. Tectonics, 33, 1936-1963. https:// doi.org/10.1002/2014TC003551

Bellahsen, N., \& Daniel, J. M. (2005). Fault reactivation control on normal fault growth: An experimental study. Journal of Structural Geology, 27, 769-780. https://doi.org/10.1016/j.jsg.2004.12.003

Bellahsen, N., Daniel, J. M., Bollinger, L., \& Burov, E. (2003). Influence of viscous layers on the growth of normal faults: Insights from experimental and numerical models. Journal of Structural Geology, 25, 1471-1485. https://doi.org/10.1016/ S0191-8141(02)00185-2

Bialas, R. W., \& Buck, W. R. (2009). How sediment promotes narrow rifting: Applications to the Gulf of California. Tectonics, 28, TC4014. https://doi.org/10.1029/2008TC002394

Bonini, M., Souriot, T., Boccaletti, M., \& Brun, J.-P. (1997). Successive orthogonal and oblique extension periods in a rift zone: Laboratory experiments with application to the Ethiopian Rift. Tectonics, 16, 347-362. https://doi.org/10.1029/96TC03935

Boutelier, D., Schrank, C., \& Regenauer-Lieb, K. (2019). 2-D finite displacements and strain from particle imaging velocimetry (PIV) analysis of tectonic analogue models with TecPIV. Solid Earth, 10, 1123-1139. https://doi.org/10.5194/se-10-1123-2019 
Brun, J.-P. (1999). Narrow rifts versus wide rifts: Inferences for the mechanics of rifting from laboratory experiments. Philosophical Transactions of the Royal Society of London. Series A: Mathematical, Physical and Engineering Sciences, 357, 695712. https://doi.org/10.1098/rsta.1999.0349

Brun, J.-P., \& Tron, V. (1993). Development of the North Viking Graben: Inferences from laboratory modelling. Sedimentary Geology, 86, 31-51. https://doi.org/10.1016/0037-0738(93)90132-O

Brune, S., \& Autin, J. (2013). The rift to break-up evolution of the Gulf of Aden: Insights from 3D numerical lithospheric-scale modelling. Tectonophysics, 607, 65-79. https://doi.org/10.1016/j. tecto.2013.06.029

Brune, S., Williams, S. E., Butterworth, N. P., \& Müller, R. M. (2016). Abrupt plate accelerations shape rifted continental margins. Nature, 536, 201-204. https://doi.org/10.1038/nature18319

Brune, S., Williams, S. E., \& Müller, D. R. (2018). Oblique rifting: The rule, not the exception. Solid Earth, 9, 1187-1206. https://doi. org/10.5194/se-9-1187-2018

Buck, W. R. (1991). Models of continental lithospheric extension. Journal of Geophysical Research, 96, 20161-20178. https://doi. org/10.1029/91JB01485

Buck, W. R. (2004). Consequences of asthenospheric variability on continental rifting. In G. D. Karner, B. Taylor, N. W. Droscoll, \& D. L. Kohlstedt (Eds.), Rheology and deformation of the lithosphere at continental margins (pp. 1-31). Columbia University Press. https://doi.org/10.7312/karn12738-002

Buck, W. R. (2006). The role of magma in the development of the AfroArabian Rift System. In G. Yirgu, C. J. Ebinger, \& P. K. H. Maguire (Eds.), The Afar Volcanic Province within the East African Rift System (Vol. 259, pp. 43-54). Geological Society, London, Special Publications. https://doi.org/10.1144/GSL.SP.2006.259.01.05

Buiter, S. J. H., Huismans, R. S., \& Beaumont, C. (2008). Dissipation analysis as a guide to mode selection during crustal extension and implications for the styles of sedimentary basins. Journal of Geophysical Research, 113, B06406. https://doi. org/10.1029/2007JB005272

Burov, E. B. (2011). Rheology and strength of the lithosphere. Marine and Petroleum Geology, 28, 1402-1443. https://doi. org/10.1016/j.marpetgeo.2011.05.008

Burov, E., \& Cloetingh, S. (1997). Erosion and rift dynamics: New thermomechanical aspects of post-rift evolution of extensional basins. Earth and Planetary Science Letters, 150, 7-26. https:// doi.org/10.1016/S0012-821X(97)00069-1

Burov, E. B., \& Watts, A. B. (2006). The long-term strength of continental lithosphere: 'Jelly sandwich' or 'crème brûlée'? GSA Today, 16, 4-10. https://doi.org/10.1130/1052-5173(2006)016<4:tltSO c>2.0.cO;2

Byerlee, J. (1978). Friction of rocks. Pure and Applied Geophysics, 116, 615-626. https://doi.org/10.1007/BF00876528

Carlo AG (Carlo Bernasconi AG webpage) (2021). https://www.carloag.ch

Chao, P., Manatschal, G., Chenin, P., Ren, J., Zhang, C., Pang, X., Zheng, J., Yang, L., \& Kusznir, N. (2021). The tectono-stratigraphic and magmatic evolution of conjugate rifted margins: Insights from the NW South China Sea. Journal of Geodynamics, 148, 101877. https://doi.org/10.1016/j.jog.2021.101877

Chenin, P., \& Beaumont, C. (2013). Influence of offset weak zones on the development of rift basins: Activation and abandonment during continental extension and breakup. Journal of Geophysical Research: Solid Earth, 118, 1698-1720. https://doi. org/10.1002/jgrb.50138
Chenin, P., James, S., Lavier, L. L., Manatschal, G., Picazo, S., Müntener, O., Karner, G. D., Figueredo, P. H., \& Johnson, C. (2019). Impact of mafic underplating and mantle depletion on subsequent rifting: A numerical modeling study. Tectonics, 38, 2185-2207. https://doi.org/10.1029/2018TC005318

Chenin, P., Manatschal, G., Decarlis, A., Schmalholz, S. M., Duretz, T., \& Beltrando, M. (2019). Emersion of distal domains in advanced stages of continental rifting explained by asynchronous crust and mantle necking. Geochemistry, Geophysics, Geosystems, 20, 3821-3840. https://doi.org/10.1029/2019GC008357

Chenin, P., Manatschal, G., Lavier, L. L., \& Erratt, D. (2015). Assessing the impact of orogenic inheritance on the architecture, timing and magmatic budget of the North Atlantic rift system: A mapping approach. Journal of the Geological Society, 172, 711-720. https://doi.org/10.1144/jgs2014-139

Chenin, P., Schmalholz, S. M., Manatschal, G., \& Duretz, T. (2020). Impact of crust-mantle mechanical coupling on the topographic and thermal evolutions during the necking phase of 'magma-poor' and 'sediment-starved' rift systems: A numerical modeling study. Tectonophysics, 786, 228472. https://doi. org/10.1016/j.tecto.2020.228472

Chorowicz, J., Collet, B., Bonavia, F., \& Korme, T. (1999). Left-lateral strike-slip tectonics and gravity induced individualisation of wide continental blocks in the western Afar margin. Eclogae Geologicae Helvetiae, 92, 149-158. https://doi.org/10.5169/seals-168656

Claringbould, J. S., Bell, R. E., Jackson, C.- A.-L., Gawthorpe, R. L., \& Odinsen, T. (2017). Pre-existing normal faults have limited control on the rift geometry of the northern North Sea. Earth and Planetary Science Letters, 475, 190-206. https://doi. org/10.1016/j.epsl.2017.07.014

Claringbould, J. S., Bell, R. E., Jackson, C.- A.-L., Gawthorpe, R. L., \& Odinsen, T. (2020). Pre-breakup extension in the northern North Sea defined by complex strain partitioning and heterogeneous extension rates. Tectonics, 39, e2019TC005924. https:// doi.org/10.1029/2019TC005924

Clifton, A. E., Schlische, R. W., Withjack, M. O., \& Ackermann, R. V. (2000). Influence of rift obliquity on fault-population systematics: Results of experimental clay models. Journal of Structural Geology, 22, 1491-1509. https://doi.org/10.1016/S0191-8141(00)00043-2

Corti, G. (2012). Evolution and characteristics of continental rifting: Analog modeling-inspired view and comparison with examples from the East African Rift System. Tectonophysics, 522-523, 133. https://doi.org/10.1016/j.tecto.2011.06.010

Corti, G., Bonini, B., Conticelli, S., Innocenti, F., Manetti, P., \& Sokoutis, D. (2003). Analogue modelling of continental extension: A review focused on the relations between the patterns of deformation and the presence of magma. Earth Science Reviews, 63, 169-247. https://doi.org/10.1016/S0012-8252(03)00035-7

Deng, C., Gawthorpe, R. L., Fossen, H., \& Finch, E. (2018). How does the orientation of a preexisting basement weakness influence fault development during renewed rifting? Insights from threedimensional discrete element modeling. Tectonics, 37, 22212242. https://doi.org/10.1029/2017TC004776

Dubois, A., Odonne, F., Massonnat, G., Lebourg, T., \& Fabre, R. (2002). Analogue modelling of fault reactivation: Tectonic inversion and oblique remobilisation of grabens. Journal of Structural Geology, 24, 1741-1752. https://doi.org/10.1016/ S0191-8141(01)00129-8

Duclaux, G., Huismans, R. S., \& May, D. A. (2020). Rotation, narrowing, and preferential reactivation of brittle structures during 
oblique rifting. Earth and Planetary Science Letters, 531, 115952. https://doi.org/10.1016/j.epsl.2019.115952

Dyksterhuis, S., Rey, P., Müller, R. D., \& Moresi, L. (2007). Effects of initial weakness on rift architecture. Geological Society, London, Special Publications, 282, 443-455. https://doi.org/10.1144/SP282.18

Ebinger, C. (2005). Continental break-up: The East African perspective. Astronomy and Geophysics, 46, 2.16-2.21. https://doi. org/10.1111/j.1468-4004.2005.46216.x

Erratt, D., Thomas, G. M., Hartley, N. R., Musum, R., Nicholson, P. H., \& Spisto, Y. (2010). North Sea hydrocarbon systems: Some aspects of our evolving insights into a classic hydrocarbon province. Geological Society, London, Petroleum Geology Conference Series, 7, 37-56. https://doi.org/10.1144/0070037

Erratt, D., Thomas, G. M., \& Wall, G. R. T. (1999). The evolution of the Central North Sea Rift. Geological Society, London, Petroleum Geology Conference Series, 5, 63-82. https://doi.org/10.1144/0050063

Handin, J. (1969). On the Coulomb-Mohr failure criterion. Journal of Geophysical Research, 74, 5343-5348. https://doi.org/10.1029/ JB074i022p05343

Henza, A. A., Withjack, M. O., \& Schlische, R. W. (2010). Normalfault development during two phases of non-coaxial extension: An experimental study. Journal of Structural Geology, 32, 16561667. https://doi.org/10.1016/j.jsg.2009.07.007

Henza, A. A., Withjack, M. O., \& Schlische, R. W. (2011). How do the properties of a pre-existing normal-fault population influence fault development during a subsequent phase of extension? Journal of Structural Geology, 33, 1312-1324. https://doi. org/10.1016/j.jsg.2011.06.010

Heron, P. J., Peace, A. L., McCaffrey, K. J. W., Welford, J. K., Wilson, R., van Hunen, J., \& Pysklywec, R. N. (2019). Segmentation of rifts through structural inheritance: Creation of the Davis Strait. Tectonics, 38, 2411-2430. https://doi.org/10.1029/2019TC005578

Hubbert, M. K. (1937). Theory of scale models as applied to the study of geologic structures. Geological Society of America Bulletin, 48, 1459-1520. https://doi.org/10.1130/GSAB-48-1459

Jaeger, J. C., \& Cook, N. G. W. (1976). Fundamentals of rock mechanics. Chapman \& Hall, Wiley. https://doi.org/10.1017/S0016 756800044897

Keep, M., \& McClay, K. R. (1997). Analogue modelling of multiphase rift systems. Tectonophysics, 273, 239-270. https://doi. org/10.1016/S0040-1951(96)00272-7

Kettermann, M., von Hagke, C., van Gent, H. W., Grützner, C., \& Urai, J. L. (2016). Dilatant normal faulting in jointed cohesive rocks: A physical model study. Solid Earth, 7, 843-856. https:// doi.org/10.5194/se-7-843-2016

Klinkmüller, M., Schreurs, G., Rosenau, M., \& Kemnitz, H. (2016). Properties of granular analogue model materials: A community wide survey. Tectonophysics, 684, 23-38. https://doi. org/10.1016/j.tecto.2016.01.017

Le Calvez, J. H., \& Vendeville, B. C. (2002). Experimental designs to model along-strike fault interaction. Journal of the Virtual Explorer, 7, 1-17. https://doi.org/10.3809/jvirtex.2002.00043

Liao, J., \& Gerya, T. (2015). From continental rifting to seafloor spreading: Insight from 3D thermo-mechanical modeling. Gondwana Research, 28, 1329-1343. https://doi.org/10.1016/j.gr.2014.11.004

Maestrelli, D., Montanari, D., Corti, G., Del Ventisette, C., Moratti, G., \& Bonini, M. (2020). Exploring the interactions between rift propagation and inherited crustal fabrics through experimental modeling. Tectonics, 39, e2020TC006211. https://doi. org/10.1029/2020TC006211
Martín-Barajas, A., González-Escobar, M., Fletcher, J. M., Pacheco, M., Oskin, M., \& Dorsey, R. (2013). Thick deltaic sedimentation and detachment faulting delay the onset of continental rupture in the Northern Gulf of California: Analysis of seismic reflection profiles. Tectonics, 32, 1294-1311. https://doi. org/10.1002/tect.20063

McClay, K. R., \& White, M. J. (1995). Analogue modelling of orthogonal and oblique rifting. Marine and Petroleum Geology, 12, 137-151. https://doi.org/10.1016/0264-8172(95)92835-K

Michon, L., \& Merle, O. (2000). Crustal structures of the Rhinegraben and the Massif Central grabens: An experimental approach. Tectonics, 19, 896-904. https://doi.org/10.1029/2000TC900015

Michon, L., \& Merle, O. (2003). Mode of lithospheric extension: Conceptual models from analogue modeling. Tectonics, 22, 1028. https://doi.org/10.1029/2002TC001435

Molnar, N. E., Cruden, A. R., \& Betts, P. G. (2017). Interactions between propagating rotational rifts and linear rheological heterogeneities: Insights from three-dimensional laboratory experiments. Tectonics, 36, 420-443. https://doi.org/10.1002/2016TC004447

Molnar, N. E., Cruden, A. R., \& Betts, P. G. (2018). Unzipping continents and the birth of microcontinents. Geology, 46, 451-454. https://doi.org/10.1130/G40021.1

Molnar, N. E., Cruden, A. R., \& Betts, P. G. (2019). Interactions between propagating rifts and linear weaknesses in the lower crust. Geosphere, 15, 1617-1640. https://doi.org/10.1130/GES02119.1

Molnar, N. E., Cruden, A. R., \& Betts, P. G. (2020). The role of inherited crustal and lithospheric architecture during the evolution of the Red Sea: Insights from three dimensional analogue experiments. Earth and Planetary Science Letters, 544, 116377. https://doi.org/10.1016/j.epsl.2020.116377

Morley, C. K. (2010). Stress re-orientation along zones of weak fabrics in rifts: An explanation for pure extension in 'oblique' rift segments? Earth and Planetary Science Letters, 297, 667-673. https://doi.org/10.1016/j.epsl.2010.07.022

Morley, C. K., Nelson, R. A., Patton, T. L., \& Munn, S. G. (1990). Transfer zones in the East African Rift System and their relevance to hydrocarbon exploration in rifts. AAPG Bulletin, 74, 1234-1253. https:// doi.org/10.1306/0C9B2475-1710-11D7-8645000102C1865D

Mulugeta, G. (1988). Squeeze box in a centrifuge. Tectonophysics, 148, 323-335. https://doi.org/10.1016/0040-1951(88)90139-4

Naliboff, J. B., Buiter, S. J. H., Péron-Pinvidic, G., Osmundsen, P. T., \& Tertealt, J. (2017). Complex fault interaction controls continental rifting. Nature Communications, 8, 1179. https://doi. org/10.1038/s41467-017-00904-x

Nelson, R. A., Patton, T. L., \& Morley, C. K. (1992). Rift-segment interaction and its relation to hydrocarbon exploration in continental rift systems. AAPG Bulletin, 76, 1153-1169. https://doi. org/10.1306/BDFF898E-1718-11D7-8645000102C1865D

Nestola, Y., Storti, F., \& Cavozzi, C. (2015). Strain rate-dependent lithosphere rifting and necking architectures in analog experiments. Journal of Geophysical Research: Solid Earth, 120, 584594. https://doi.org/10.1002/2014JB011623

Oliveira, M. E., Gomes, A. S., Rosas, F. M., Duarte, J. C., França, G. S., Almeida, J. C., \& Fuchk, R. A. (in review). Double-rift nucleation above inherited crustal weaknesses: Insights from $2 \mathrm{D}$ numerical models. Tectonophysics.

Osagiede, E. E., Rosenau, M., Rotevatn, A., Gawthorpe, R., Jackson, C.- A.-L., \& Rudolf, M. (2021). Influence of zones of pre-existing crustal weakness on strain localization and partitioning during rifting: Insights from analog modeling using high-resolution 
3D digital image correlation. Tectonics, 40, e2021TC006970. https://doi.org/10.1029/2021TC006970

Panien, M., Schreurs, G., \& Pfiffner, A. (2006). Mechanical behaviour of granular materials used in analogue modelling: Insights from grain characterisation, ring-shear tests and analogue experiments. Journal of Structural Geology, 28, 17101724. https://doi.org/10.1016/j.jsg.2006.05.004

Phillips, T. B., Fazlikhani, H., Gawthorpe, R. L., Fossen, H., Jackson, C.- A.-L., Bell, R. E., Faleide, J. I., \& Rotevatn, A. (2019). The influence of structural inheritance and multiphase extension on rift development, the northern North Sea. Tectonics, 38, 40994126. https://doi.org/10.1029/2019TC005756

Ramberg, H. (1981). Gravity, deformation and the earth's crust. Academic Press.

Reeve, M. T., Bell, R. E., Duffy, O. B., Jackson, C.- A.-L., \& Sansom, E. (2015). The growth of non-colinear normal fault systems; What can we learn from 3D seismic reflection data? Journal of Structural Geology, 70, 141-155. https://doi.org/10.1016/j.jsg.2014.11.007

Reiter, K. (2021). Stress rotation-Impact and interaction of rock stiffness and faults. Solid Earth, 12, 1287-1307. https://doi. org/10.5194/se-12-1287-2021

Rudolf, M., Boutelier, D., Rosenaus, M., Schreurs, G., \& Oncken, O. (2016). Rheological benchmark of silicone oils used for analog modeling of short- and long-term lithospheric deformation. Tectonophyiscs, 684, 12-22. https://doi.org/10.1016/j. tecto.2015.11.028

Ruh, J. B. (2019). Effects of fault-weakening processes and oblique intracontinental rifting and subsequent inversion. American Journal of Science, 319, 315-338. https://doi.org/10.2475/04.2019.03

Samsu, A., Cruden, A. R., Hall, M., Micklethwaite, S., \& Denyszyn, S. W. (2019). The influence of basement faults on local extension directions: Insights from potential field geophysics and field observations. Basin Research, 31, 782-807. https://doi. org/10.1111/bre.12344

Samsu, A., Cruden, A. R., Molnar, N. E., \& Weinberg, R. F. (2021). Inheritance of penetrative basement anisotropies by extension-oblique faults: Insights from analogue experiments. Tectonics, 40, e2020TC006596. https://doi. org/10.1029/2020TC006596

Saria, E., Calais, E., Stamps, D. S., Delvaux, D., \& Hartnady, C. J. H. (2014). Present-day kinematics of the East African Rift. Journal of Geophysical Research: Solid Earth, 119, 3584-3600. https:// doi.org/10.1002/2013JB010901

Schlagenhauf, A., Manighetti, I., Malavieille, J., \& Dominguez, S. (2008). Incremental growth of normal faults: Insights from a laser-equipped analog experiment. Earth and Planetary Science Letters, 273, 299-311. https://doi.org/10.1016/j.epsl.2008.06.042

Tron, V., \& Brun, J.-P. (1991). Experiments on oblique rifting in brittle-ductile systems. Tectonophysics, 188, 71-84. https://doi. org/10.1016/0040-1951(91)90315-J

Twiss, R. J., \& Moore, E. M. (1992). Structural geology. W.H. Freeman and Company.

Van Wijk, J. W. (2005). Role of weak zone orientation in continental lithosphere extension. Geophysical Research Letters, 31, L02303. https://doi.org/10.1029/2004GL022192

Virgo, S., Abe, S., \& Urai, J. L. (2014). The evolution of crack seal vein and fracture networks in an evolving stress field: Insights from Discrete Element Models of fracture sealing. Journal of Geophysical Research: Solid Earth, 119, 8708-8727. https://doi. org/10.1002/2014JB011520
Wang, L., Maestrelli, D., Corti, G., Zou, Y., \& Shen, C. (2021). Normal fault reactivation during multiphase extension: Analogue models and application to the Turkana depression, East Africa. Tectonophysics, 811, 228870. https://doi.org/10.1016/j.tecto.2021.228870

Weijermars, R., \& Schmeling, H. (1986). Scaling of Newtonian and non-Newtonian fluid dynamics without inertia for quantitative modelling of rock flow due to gravity (including the concept of rheological similarity). Physics of the Earth and Planetary Interiors, 43, 316-330. https://doi. org/10.1016/0031-9201(86)90021-X

Wenker, S., \& Beaumont, C. (2018). Can metasomatic weakening result in the rifting of cratons? Tectonophysics, 746, 3-21. https:// doi.org/10.1016/j.tecto.2017.06.013

Wijns, C., Weinberg, R., Gessner, K., \& Moresi, L. (2005). Mode of crustal extension determined by rheological layering. Earth and Planetary Science Letters, 236, 120-134. https://doi. org/10.1016/j.epsl.2005.05.030

Wilson, J. T. (1966). Did the Atlantic close and then re-open? Nature, 211, 676-681. https://doi.org/10.1038/211676a0

Withjack, M. O., Henza, A. A., \& Schlische, R. W. (2017). Threedimensional fault geometries and interactions within experimental models of multiphase extension. AAPG Bulletin, 101, 1767-1789. https://doi.org/10.1306/02071716090

Zwaan, F., Chenin, P., Erratt, D., Manatschal, G., \& Schreurs, G. (2021a). Complex rift patterns, a result of interacting crustal and mantle weaknesses, or multiphase rifting? Insights from analogue models. Solid Earth, 12, 1473-1495. https://doi. org/10.5194/se-12-1473-2021

Zwaan, F., Chenin, P., Erratt, D., Manatschal, G., \& Schreurs, G. (2021b). PIV and topographic analysis data from analogue experiments involving $3 D$ structural inheritance and multiphase rifting. GFZ Data Services. https://doi.org/10.5880/ fidgeo.2021.042

Zwaan, F., Corti, G., Keir, D., \& Sani, F. (2020a). A review of tectonic models for the rifted margin of Afar: Implications for continental break-up and passive margin formation. Journal of African Earth Science, 164, 103649. https://doi.org/10.1016/j. jafrearsci.2019.103649

Zwaan, F., Corti, G., Keir, D., \& Sani, F. (2020b). Analogue modelling of marginal flexure in Afar, East Africa: Implications for passive margin formation. Tectonophysics, 796, 228595. https://doi. org/10.1016/j.tecto.2020.228595

Zwaan, F., Corti, G., Sani, F., Keir, D., Muluneh, A. A., Illsley-Kemp, F., \& Papini, M. (2020). Structural analysis of the Western Afar Margin, East Africa: Evidence for multiphase rotational rifting. Tectonics, 39, e2019TC006043. https://doi.org/10.1029/2019T $\mathrm{C} 006043$

Zwaan, F., \& Schreurs, G. (2017). How oblique extension and structural inheritance influence rift segment interaction: Insights from 4D analog models. Interpretation, 5, SD119-SD138. https://doi.org/10.1190/INT-2016-0063.1

Zwaan, F., \& Schreurs, G. (2021). Analogue modelling of continental rifting: An overview. In G. Peron-Pinvidic (Ed.), Rifted margins. ISTE-WILEY. https://www.researchgate.net/publi cation/349536310_Analogue_modelling_of_continental_rifti ng_an_overview

Zwaan, F., Schreurs, G., \& Adam, J. (2018). Effects of sedimentation on rift segment evolution and rift interaction in orthogonal and oblique extensional settings: Insights from analogue models analysed with 4D X-ray computed tomography and digital 
volume correlation techniques. Global and Planetary Change, 171, 110-133. https://doi.org/10.1016/j.gloplacha.2017.11.002

Zwaan, F., Schreurs, G., \& Buiter, S. J. H. (2019). A systematic comparison of experimental set-ups for modelling extensional tectonics. Solid Earth, 10, 1063-1097. https://doi.org/10.5194/ se-10-1063-2019

Zwaan, F., Schreurs, G., Gentzmann, R., Warsitzka, M., \& Rosenau, M. (2018). Ring-shear test data of quartz sand from the Tectonic Modelling Lab of the University of Bern (CH). GFZ Data Services. https://doi.org/10.5880/fidgeo.2018.028

Zwaan, F., Schreurs, G., Naliboff, J., \& Buiter, S. J. H. (2016). Insights into the effects of oblique extension on continental rift interaction from 3D analogue and numerical models. Tectonophysics, 693, 239-260. https://doi.org/10.1016/j. tecto.2016.02.036

Zwaan, F., Schreurs, G., Ritter, M., Santimano, T., \& Rosenau, M. (2018). Rheology of PDMS-corundum sand mixtures from the
Tectonic Modelling Lab of the University of Bern (CH). GFZ Data Services. https://doi.org/10.5880/fidgeo.2018.023

Zwaan, F., Schreurs, G., \& Rosenau, M. (2020). Rift propagation in rotational versus orthogonal extension: Insights from 4D analogue models. Journal of Structural Geology, 135, 103946. https://doi.org/10.1016/j.jsg.2019.103946

How to cite this article: Zwaan, F., Chenin, P., Erratt, D., Manatschal, G., \& Schreurs, G. (2021). Competition between 3D structural inheritance and kinematics during rifting: Insights from analogue models. Basin Research, 00, 1-31. https://doi. org/10.1111/bre.12642 

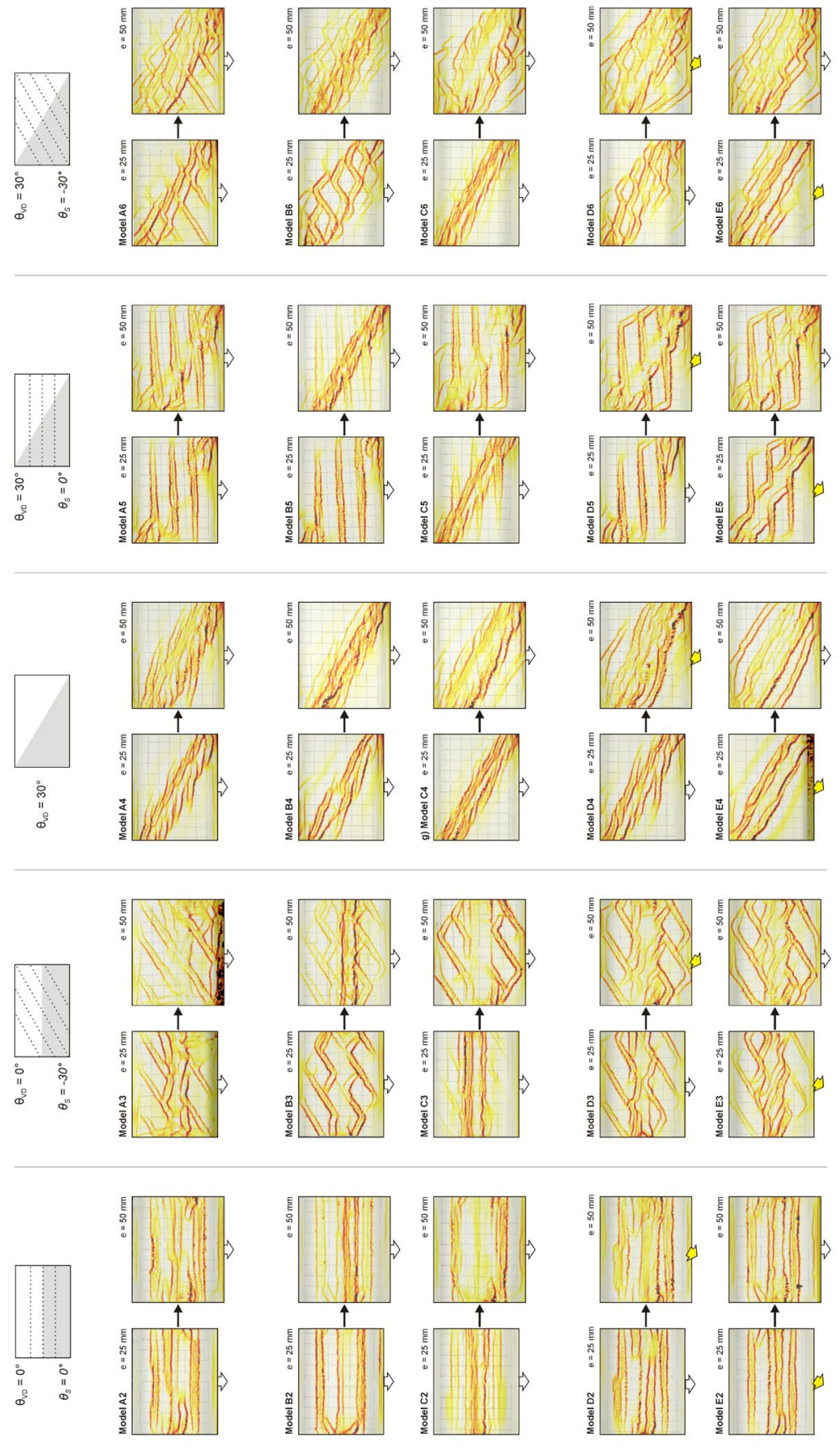

商
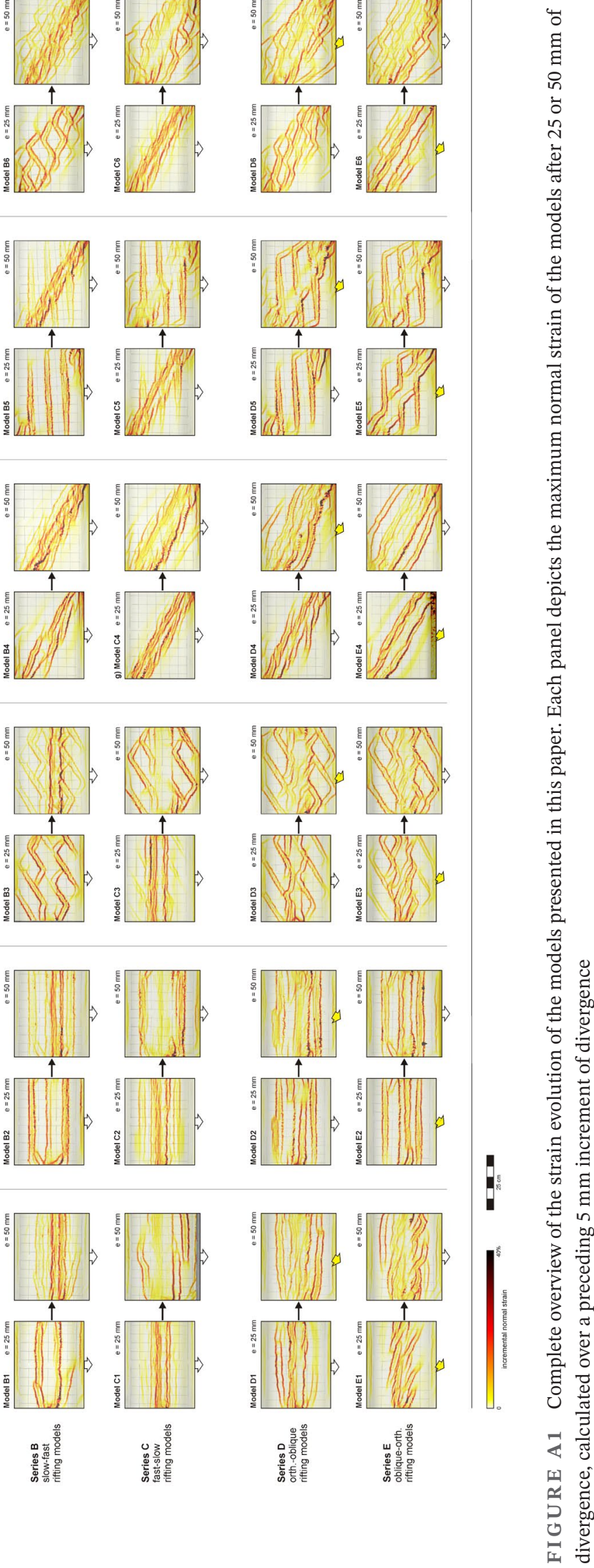

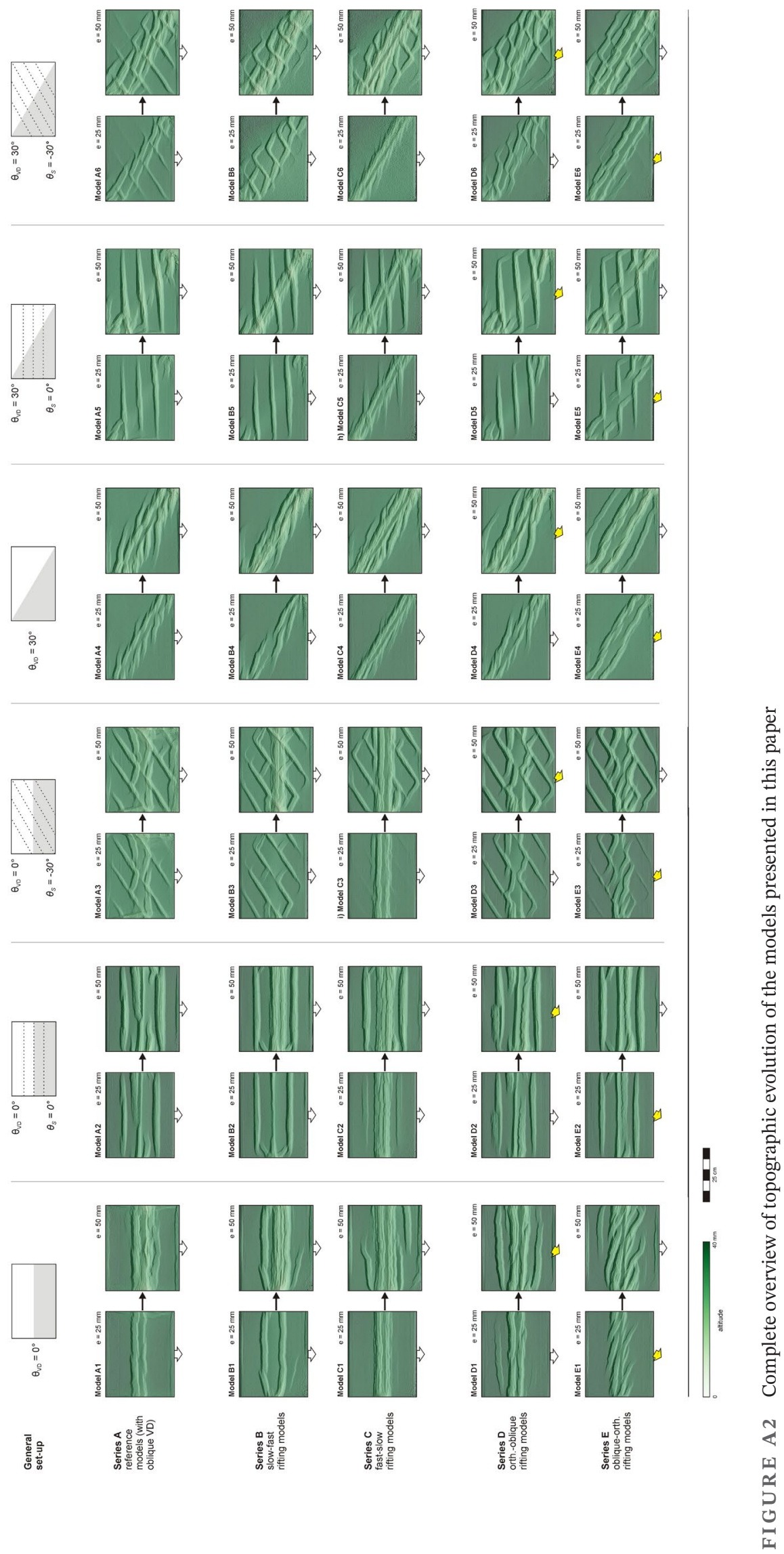